\title{
Effects of Wind-Wave Misalignment on a Wind Turbine Blade Mating Process: Impact Velocities, Blade Root Damages and Structural Safety Assessment
}

\author{
Amrit Shankar Verma ${ }^{1,2,3} \cdot$ Zhiyu Jiang $^{4} \cdot$ Zhengru Ren $^{1,2} \cdot$ Zhen Gao $^{1,2} \cdot$ Nils Petter Vedvik $^{5}$
}

Received: 29 January 2019 / Accepted: 28 August 2019 / Published online: 28 September 2020

(C) The Author(s) 2020

\begin{abstract} connections

\section{Article Highlights}

- The effects of wind-wave misalignments on the blade root mating process on a monopile-type offshore wind turbine is investigated.

- The collinear wind-wave conditions cause sideways impact, whereas head-on impact is developed dominantly due to misaligned windwave conditions.

- The sideways' impact of the guide pin with hub is more critical than the head-on impact, and the failure criteria in the root laminate are met at a relatively low velocity of impact.

- Collinear wind-wave condition is found to have the lowest percentage of safe domain for mating task.
\end{abstract}

Most wind turbine blades are assembled piece-by-piece onto the hub of a monopile-type offshore wind turbine using jack-up crane vessels. Despite the stable foundation of the lifting cranes, the mating process exhibits substantial relative responses amidst blade root and hub. These relative motions are combined effects of wave-induced monopile motions and wind-induced blade root motions, which can cause impact loads at the blade root's guide pin in the course of alignment procedure. Environmental parameters including the wind-wave misalignments play an important role for the safety of the installation tasks and govern the impact scenarios. The present study investigates the effects of wind-wave misalignments on the blade root mating process on a monopile-type offshore wind turbine. The dynamic responses including the impact velocities between root and hub in selected wind-wave misalignment conditions are investigated using multibody simulations. Furthermore, based on a finite element study, different impact-induced failure modes at the blade root for sideways and head-on impact scenarios, developed due to wind-wave misalignment conditions, are investigated. Finally, based on extreme value analyses of critical responses, safe domain for the mating task under different wind-wave misalignments is compared. The results show that although misaligned wind-wave conditions develop substantial relative motions between root and hub, aligned wind-wave conditions induce largest impact velocities and develop critical failure modes at a relatively low threshold velocity of impact.

Keywords Wind turbine blade $\cdot$ Wind-wave misalignment $\cdot$ Monopile $\cdot$ Marine operation · Finite element analysis · T-bolt

\section{Amrit Shankar Verma}

amrit.s.verma@ntnu.no

1 Department of Marine Technology, Norwegian University of Science and Technology (NTNU), Trondheim, Norway

2 Centre for Marine Operations in Virtual Environments (SFI MOVE), NTNU, Trondheim, Norway

3 Faculty of Aerospace Engineering, Delft University of Technology (TU Delft), 2629 HS Delft, Netherlands

4 Department of Engineering Sciences, University of Agder, 4879 Grimstad, Norway

5 Department of Mechanical and Industrial Engineering, NTNU, Trondheim, Norway

\section{Introduction}

In order to resolve the issues related to global warming and climate change, there is a continuous demand for renewable sources of energy. In Europe, wind energy ranks second in terms of power generation (Wind Europe 2017a), and immense political and scientific interest is placed on the growth of offshore wind turbines (OWTs). Monopile-type OWTs are the most popular choice of turbines in shallow waters, and currently account for more than $87 \%$ of the market share (Wind Europe 2017b). One of the main challenges in the industry includes high installation and assembly cost (Molla 2015) associated with the project cycle of OWTs, and therefore, recent trends involve deploying large size OWTs. This facilitates having less number of turbine units at an offshore farm, thus reducing the overall installation cost. However, several safety issues are inevitably present during the installation of bigger and heavier turbine components. For example, components like blades and nacelle are structurally delicate and demand absolute precision during transportation and installation. 
Generally, blades of a monopile-type offshore wind turbine are installed using jack-up crane vessels (Verma et al. 2017; Verma et al. 2019a; Ren et al. 2018a) (Figure 1a). Individual pieces are hoisted to the hub, and blade root consisting of several bolted connections, together with the guide pin, is mated with the hub's flange holes (Verma et al. 2019b). The guide pins are long-sized bolts (Figure $1 \mathrm{~b}-\mathrm{c}$ ) and are inserted in the blade root to visually aid the offshore crew (present in the nacelle) while performing the mating task.

Despite the stable foundation of the jack-up crane vessels, the mating process suffers substantial relative responses amidst blade root and hub (Jiang et al. 2018; Ren et al. 2018b; Ren et al. 2019). The blade root motions are a result of wind-induced loads on the lifted blade, whereas the hub responses are caused by wave actions on the preassembled monopile structures. Note that monopiles are large diameter structures fixed to the seabed and have low damping characteristics (Jiang 2018). For example, the monopiles have deficient structural, hydrodynamic and soil-damping attributes. The damping is even more critical during the installation phase as the aerodynamic damping from the rotating blades is missing. Thus, large dynamic amplification of tower top responses develops and contributes to excessive relative motions while performing the mating task. This can induce impact loads at the guide pin during the alignment process, causing critical damages at the blade root and

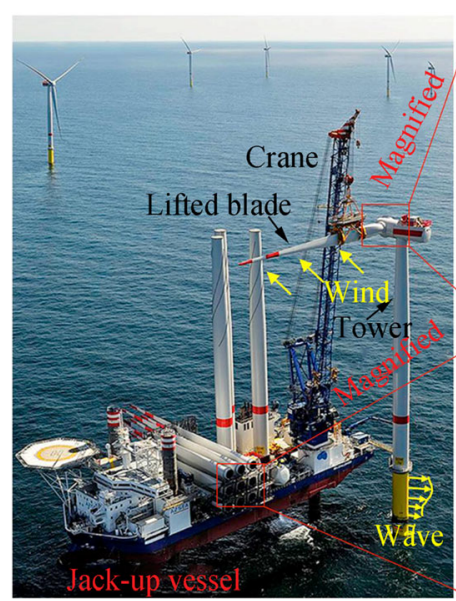

(a) Blade mating task using jack-up crane vessel

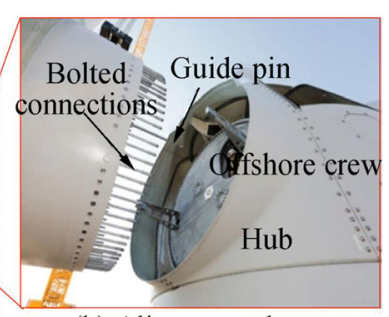

(b) Alignment phase

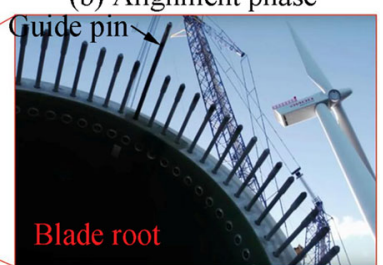

(c) Inserted guide pin into blade root
Figure 1 Blade root mating process (https://orsted.com/en) (https:// vessels.offshorewind.biz/vessels/sea challenger) (https://www.siemens. com) thus, failure of installation task. Verma et al. (2019a) investigated impact assessment of wind turbine blade root during offshore mating process where relative responses under aligned wind-wave conditions were investigated. Furthermore, damage assessment at the blade root was studied, and bending of guide pin and delamination of root laminate were found as failure modes. Nevertheless, mating operations under misaligned wind-wave conditions were not considered, and damages for such scenarios were not assessed. In practice, for an offshore site, wind-wave misalignments are present for all ranges of wind speeds, and therefore, it is important to investigate such effects for the success of the wind turbine blade mating process. Wind-wave misalignment is the measure of temporal difference between the wind direction and mean wave directions (Van Vledder 2013), where highest degree of misalignments is found at low wind speeds, and minor misalignments are found at high wind speeds ( $\mathrm{Li}$ et al. 2015; Van Vledder 2013; Bachynski et al. 2014).

Figure $2 \mathrm{a}-\mathrm{d}$ present the relative frequency of wind direction, mean wave directions and misalignment between wind and waves for the North Sea centre. It can be clearly seen that though the wind and waves are spread out in all directions, the misalignment between wind-wave is mostly concentrated between $0^{\circ}$ and $90^{\circ}$. Majority of the misalignment occurs till $30^{\circ}$, with frequency being less than $5 \%$ for wind-wave misalignment greater than $60^{\circ}$ (Bachynski et al. 2014). Currently, there are limited published literature sources (Jiang et al. 2018; Verma et al. 2019c; Verma et al. 2019d; Verma et al. 2020a; Verma et al. 2020b) dealing with the effects of wind-wave misalignment on the installation phases of OWTs, although several studies in the past emphasised operational and parked conditions of OWTs for design purposes. Barj et al. (2014), Bachynski et al. (2014) and Zhou et al. (2017) investigated the effect of misalignment on the operational loads for floating OWTs, whereas Fischer et al. (2011) investigated the effect of misalignment on monopile-type OWTs. The response parameters of interest for such assessments were tower top motions, bending moments and fatigue damages. On the other hand, in this study, the mating process of blade is studied, and therefore, the response parameters of interest are related to the critical event that can cause failure of the installation task. These include (1) impact velocity between root and hub during mating, (2) impact-induced damages at the blade root and (3) structural safety assessment of the mating task for a given wind-wave misalignment condition. 
The present paper investigates the effect of wind-wave misalignment for the blade root mating process where dynamic responses including the impact velocities in selected wind-wave misalignment conditions are investigated using multibody simulations in HAWC2 (Larsen and Hansen 2007). Furthermore, based on a finite element study in Abaqus/explicit (Hibbitt et al. 2016), impact-induced failure modes at the blade root are discussed. Finally, safe domain for the mating task is compared for different wind-wave misalignment conditions. The remainder of the paper proceeds as follows. Section 2 presents the analysis procedure and identifies relevant response parameter for investigating effects of wind-wave misalignment. Section 3 presents the material and modelling methods. Section 4 presents and discusses the results. Finally, Section 5 concludes the paper.

\section{Response Parameters and Analysis Procedure}

There are three response parameters identified in this paper to investigate the effects of wind-wave misalignment on the wind turbine blade mating process and are described below:

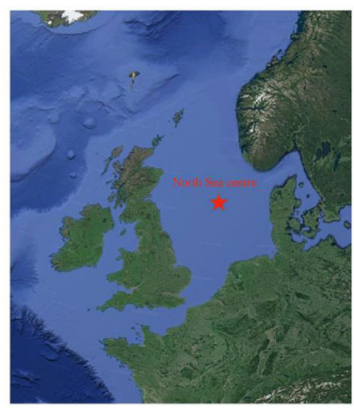

(a) North Sea centre

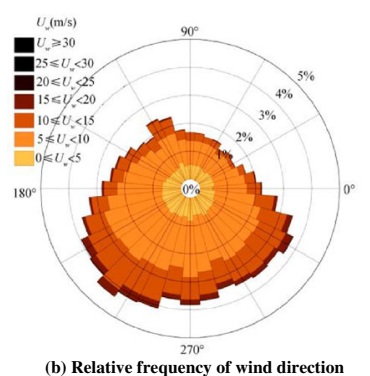

(b) Relative frequency of wind directio
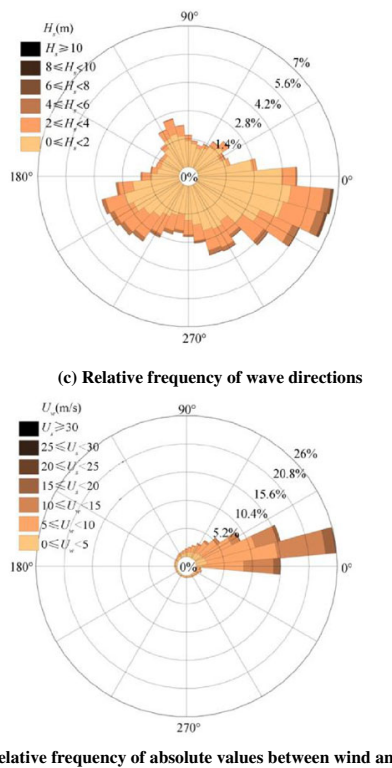

d) Relative frequency of absolute values between wind and wave (defined as "wind-wave misalignment")
Figure 2 Different wind and wave directions (wind and wave direction corresponds to a compass $-0^{\circ}$ represents East, $90^{\circ}$ North, $180^{\circ}$ West and $270^{\circ}$ represents South)

\subsection{Impact Velocity between Root and Hub}

This is the most critical response parameter of interest for the blade mating task and determines the impact scenarios for the blade root's guide pin. These responses are governed partially by wind-induced blade root responses and partially by wave-induced hub motions. Impact velocities in two different directions and corresponding impact scenarios are defined. (1) Impact velocity in the side-side direction $\left(V_{x}^{\text {imp }}\right)$ causes head-on impact of the guide pin (Figure 3). Here, contact region of the guide pin lies along its axial direction. $V_{x}^{\text {imp }}$ is defined as relative velocity among root and hub in global $x$-direction: $V_{x}^{\text {hub }}-V_{x}^{\text {root }}$. While, (2) impact velocity in the fore-aft direction ( $\left.V_{y}^{\text {imp }}\right)$ causes sideways' impact of the guide pin, and contact region lies along its transverse direction. $V_{y}^{\text {imp }}$ is defined as relative velocity between root and hub in the global $y$-direction: $V_{y}^{\text {hub }}-V_{y}^{\text {root }}$. These responses vary with wind-wave misalignment and are obtained by global response analysis of the installation system.

\subsection{Damage Assessment for a Critical Location at the Blade Root}

A wind turbine blade usually includes several T-bolt connections attached at its root (Ketele 2013; Martınez et al. 2011). A T-bolt connection comprises of an assembly of steel bolt and barrel nut, which are drilled into the blade root laminate (Brøndsted and Nijssen 2013). In Verma et al. (2019a), it was found that impact loads at blade root causes through-the-thickness tensile normal stresses $\left(\sigma_{33}>0\right)$. This leads to delamination of the plies at location $z$ of the blade root (Figure 4), which is the most critical location of failure. In this paper, damage assessment at location $z$ is performed for both contact scenarios - sideways' impact and head-on impact, and allowable impact velocities in the fore-aft ( $\left.V_{y}^{\text {allow }}\right)$ and side-side direction $\left(V_{x}^{\text {allow }}\right)$ are obtained. A normalised failure index $\left(I_{f}^{z}\left(S_{33}\right)\right)$ is defined which represents stress exposure factor at location $z$ and is given by:

$I_{f}^{z}\left(S_{33}\right)=\left(\frac{\sigma_{33}^{z}}{Z^{T}}\right)$

where $\sigma_{33}^{z}$ is the through-the-thickness tensile normal stresses at location $z$, and $Z^{T}$ denotes through-the-thickness tensile strength. Note that $I_{f}^{z}\left(S_{33}\right) \geq 1$ represents failure in the root laminate at position $z$. 


\subsection{Structural Safety Assessment of the Mating Task for a Sea State with Given Wind-Wave Misalignment}

This response parameter measures whether the sea state with a given wind-wave misalignment condition is safe or not for the mating task. Here, extreme value analysis is performed for velocity of impact in both, fore-aft $\left(V_{y}^{\mathrm{imp}}\right)$ and side-side direction $\left(V_{x}^{\text {imp }}\right)$, and corresponding extreme value distributions is obtained for load cases with different wind-wave misalignment conditions.

Furthermore, for a target safety level, characteristic extreme responses $\left(V_{x}^{\text {char }}, V_{y}^{\text {char }}\right)$ are obtained (Verma et al. 2019c) and are compared with allowable impact velocities $\left(V_{x}^{\text {allow }}, V_{y}^{\text {allow }}\right)$. Only those sea states are considered safe $\left(x_{i} \in S\right)$ for the mating task in which the characteristic extreme responses are less than allowable impact velocities in both fore-aft and side-side direction. A criterion was proposed in the previous work (Verma et al. 2019c) for safety assessment of mating task and is given by:

$$
\begin{aligned}
& \forall x_{i} \in H_{s}, T_{p}, U_{w}, \beta_{\text {wave }} \\
& \text { if } V_{x}^{\text {char }} \leq V_{x}^{\text {allow }} \text { and } V_{y}^{\text {char }} \leq V_{y}^{\text {allow }} \\
& \text { then } x_{i} \in S \text { (sea-state safe for mating) } \\
& \text { else } x_{i} \notin S \text { (unsafe) }
\end{aligned}
$$

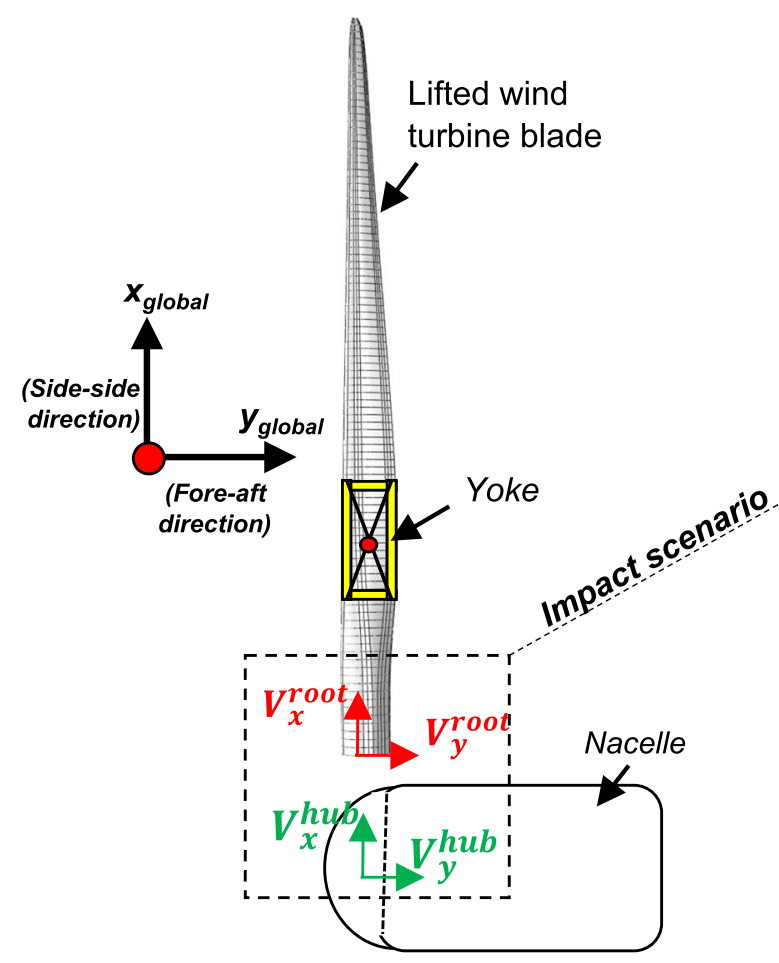

Figure 3 Illustration of impact scenarios during the blade mating process where $x_{i}$ is the load case considered for analysis, $H_{s}$ is the significant wave height, $T_{p}$ is the wave spectral peak period, $U_{w}$ is the mean wind speed at hub height, $\beta_{\text {wave }}$ is the degree of misalignment for wind-wave, $V_{x}^{\text {char }}$ and $V_{y}^{\text {char }}$ are characteristic extreme responses corresponding to a target safety level in side-side and fore-aft direction of the installation system respectively, and $V_{x}^{\text {allow }}, V_{y}^{\text {allow }}$ are allowable impact velocities in side-side and fore-aft direction, respectively. It is to be also noted that the target exceedance level for calculating the characteristic extreme responses from extreme value distributions is considered as $10^{-2}$ per operation in this study. This value corresponds to the consequence level where there are no damages developed in the composite root laminate, and another mating trial is possible after replacing damaged guide pins (Verma et al. 2019c). The target exceedance level of $10^{-2}$ for the response parameters we considered here corresponds to a target safely level with a failure probability of $10^{-2}$, representing 1 failure per 100 operations (and corresponding consequence), and is based on such incidents reported in the industry.

\section{Analysis Procedure}

Figure 5 presents the analysis procedure followed in this study for investigating the effect of wind-wave misalignment on the wind turbine blade mating process. There are three distinct yet interrelated steps, where each step

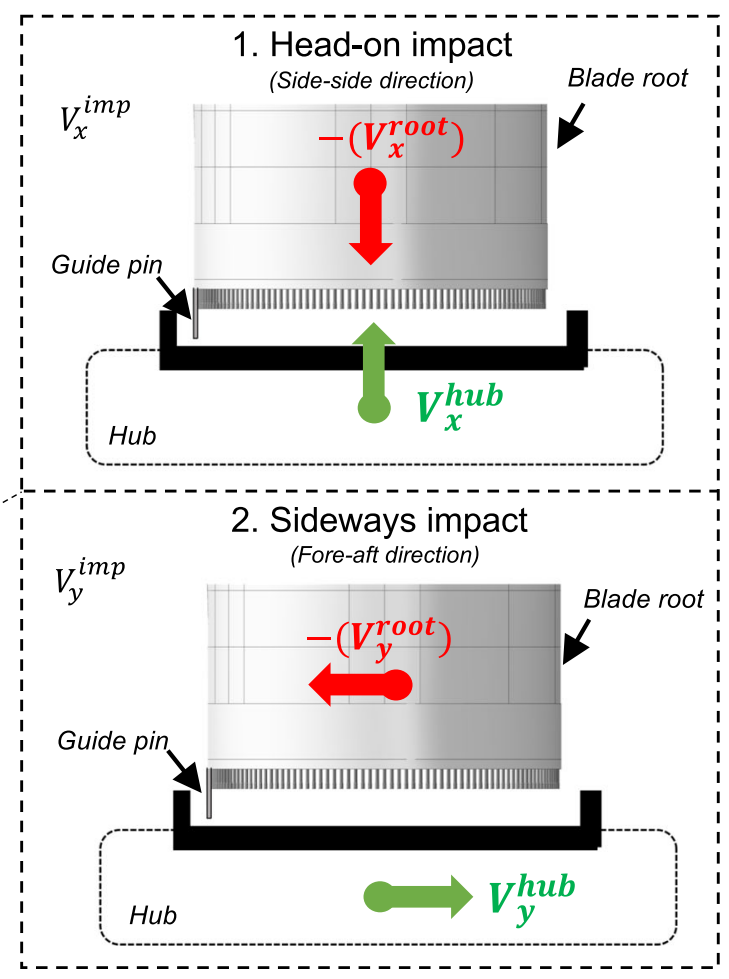




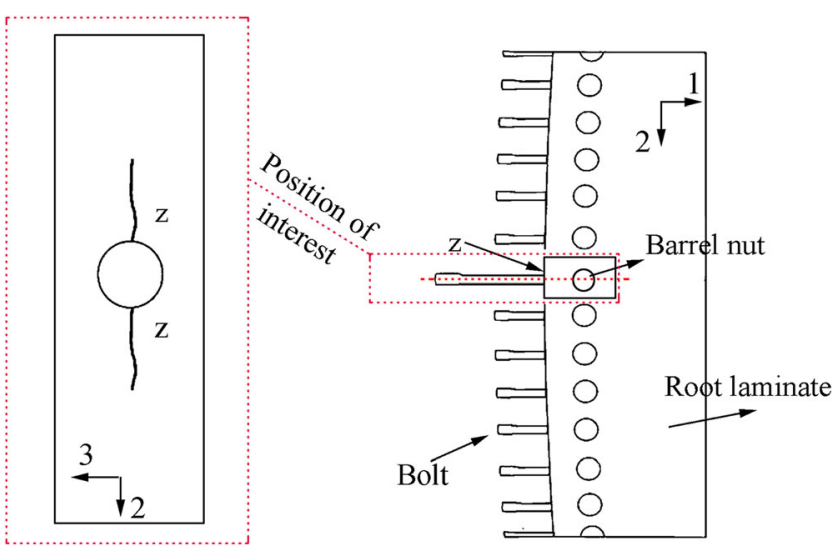

Figure 4 Position of interest at the blade root for assessment

emphasises on the quantification of the above-discussed response parameters.

The first step includes numerical modelling of the mating process in HAWC2 code (Larsen and Hansen 2007), where four different wind-wave misalignment conditions $\left(\beta_{\text {wave }}=\right.$ $0^{\circ}, 30^{\circ}, 60^{\circ}, 90^{\circ}$ ) are considered for time domain analysis. Note that the choice of wind-wave misalignment for the analysis is site-specific and represents conditions for the North Sea centre in this study. The hub motions and blade root motions are calculated and finally $V_{y}^{\mathrm{imp}}$ and $V_{x}^{\mathrm{imp}}$ are obtained for given wind-wave misalignment conditions.

The second step is impact assessment of the blade root with hub using finite element analysis. The response parameter $I_{f}^{z}$
$\left(S_{33}\right)$ is evaluated for both impact scenarios, and allowable impact velocities $\left(V_{x}^{\text {allow }}, V_{y}^{\text {allow }}\right)$ are obtained for impact scenarios in fore-aft and side-side direction.

The final step is the structural safety assessment of the mating task for given wind-wave misalignment conditions. The extreme value analysis is performed for the response parameter $V_{x}^{\text {imp }}$ and $V_{y}^{\text {imp }}$, and for a target safety level of $10^{-2}$ per operation, characteristic extreme responses $\left(V_{x}^{\text {char }}, V_{y}^{\text {char }}\right)$ are obtained for different misalignments. These characteristic responses are then compared with allowable level of impact velocities $\left(V_{x}^{\text {allow }}, V_{y}^{\text {allow }}\right)$, and only those sea states $\left(x_{i}\right)$ are considered safe for the mating task for which the criteria defined by Eq. (2) are satisfied. Finally, an overall safe domain for the mating task which consists of all safe sea states ( $\forall x_{i} \in$ $S)$ is compared for different wind-wave misalignment conditions.

\section{Material and Modelling Methods}

The mating process of DTU $10 \mathrm{MW}$ wind turbine blade (Bak et al. 2013) is considered in this article, and thus, all the parameters used for modelling are derived from DTU $10 \mathrm{MW}$ report (Bak et al. 2013). Here, the modelling details of the installation system using multibody dynamics are described first. Then, the finite element modelling information for impact analysis between blade root and hub for different scenarios are addressed.

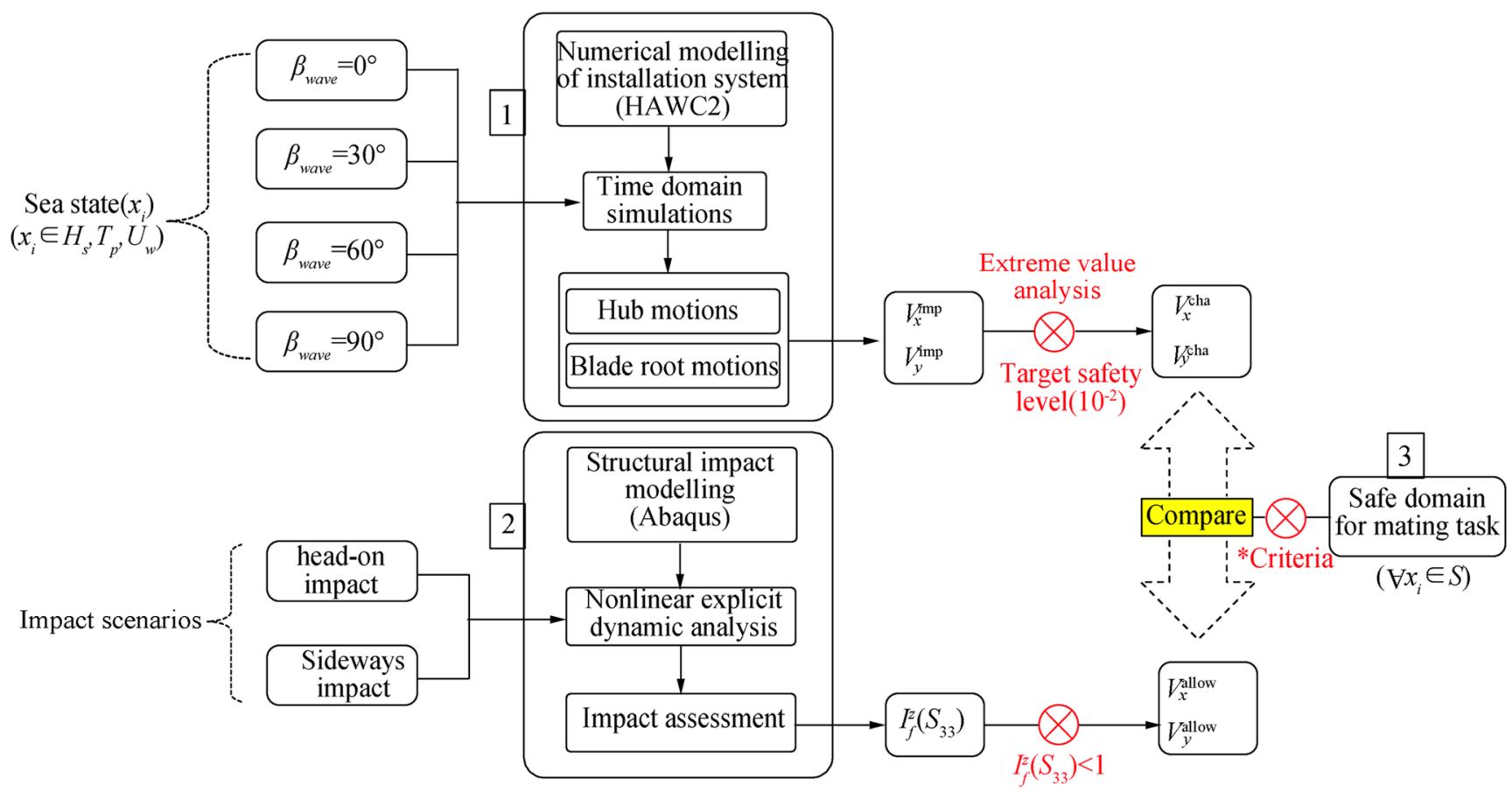

Figure 5 Analysis procedure considered in this study 


\subsection{Numerical Modelling of Installation System}

The installation system is modelled in HAWC2 numerical code (Larsen and Hansen 2007). The code can simulate dynamics of the wind turbines in the time domain considering various effects such as wind and waves. The installation system consists of two independent sub-systems - (1) preassembled monopile sub-system, and (2) single-blade lift sub-system (Figure 6). Different modelling aspects are considered in HAWC2 and are discussed below.

\section{Structural Model}

In the HAWC2 code, the structural formulation of the turbine components depends upon multibody dynamics. The first structural system, i.e. (1) preassembled monopile system consists of a monopile, along with a turbine tower, a nacelle and a hub. The components of this sub-system are grouped into several flexible bodies, and are modelled with Timoshenko beam elements linked through a coupling joint. Large rotations and large displacements are permissible at these joints; however, only small deflections are allowed within each body.

The (2) single-blade lift-sub-system on the other hand consists of the wind turbine blade, yoke, tugger lines, lift and sling wires connected to a fixed crane tip. The wind turbine blade is discretised with Timoshenko beam elements, and is defined as one single body. The yoke is added as a concentrated rigid body defined at the mass centre of the blade. The tugger lines are $10 \mathrm{~m}$ long and consist of cable bodies joined by spherical joints (Verma et al. 2019a). It is to be noted that the effect of jack-up crane vessel is ignored in this study as the vessel is generally stable due to load bearing legs, and thus has a minor contribution to crane tip responses. The structural characteristics of components used in the modelling of installation system are also mentioned in Table 1.

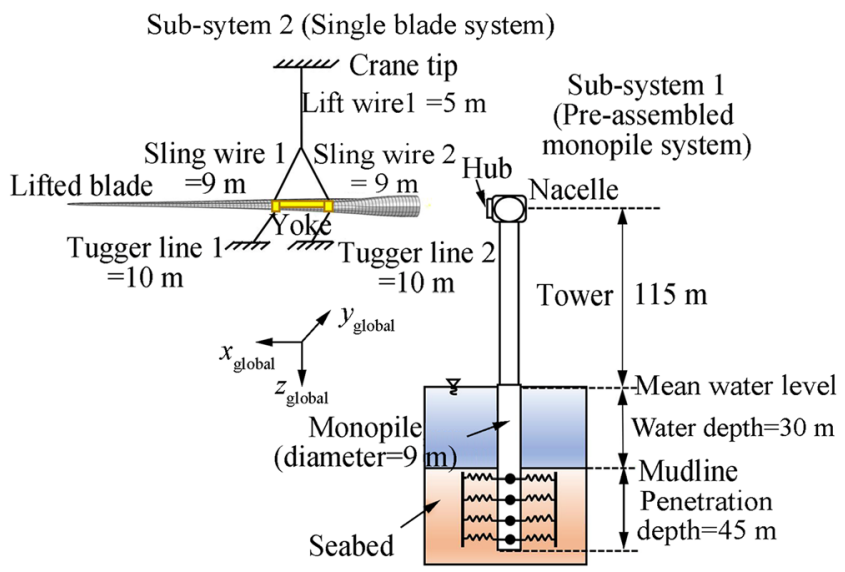

Figure 6 Description of numerical modelling of installation system
Table 1 Modelling parameters of installation system used in HAWC2

\begin{tabular}{lc}
\hline Parameter & Values \\
\hline Diameter of monopile (m) & 9 \\
Pile penetrating depth (m) & 45 \\
Water depth (m) & 30 \\
Eigen period - first fore-aft mode (s) & 4.2 \\
Damping ratio - first fore-aft mode (\%) & 1 \\
Blade mass (t) & 41.7 \\
Blade length (m) & 86.4 \\
Blade root diameter (m) & 5.4 \\
Yoke weight (t) & 50 \\
\hline
\end{tabular}

\section{Pile-Soil Interaction Model}

The monopile support structure along with the characteristics of soil layers used in this study is based on the work of Velarde (2016), where the foundation for DTU $10 \mathrm{MW}$ reference turbine was designed. In Velarde (2016), only the non-linear $p-y$ curve corresponding to soil lateral stiffness was reported and this makes the basis for pile-soil interaction model in our study. The pile diameter is around $9 \mathrm{~m}$ and has a penetration depth of $45 \mathrm{~m}$. The distributed springs model is utilised, which considers the pile as a flexible component having lateral springs spread around the soil layer.

\section{Wave-Induced Hydrodynamic Model}

Morison equation (Morison et al. 1950) is used to calculate hydrodynamic wave-induced loads exerted on the monopile. The equation consists of inertial as well as drag-associated terms and is given by:

$$
\begin{aligned}
f_{s}= & \rho C_{m} \frac{\pi D^{2}}{4} \ddot{x}_{w}-\rho\left(C_{m}-1\right) \frac{\pi D^{2}}{4} \ddot{\eta}_{1} \\
& +\frac{1}{2} \rho C_{d} D\left(\dot{x_{w}}-\dot{\eta_{1}}\right)\left|\dot{x_{w}}-\dot{\eta_{1}}\right|
\end{aligned}
$$

where $\rho$ is defined as the density of sea water, $D$ is the monopile diameter, and $C_{m}$ and $C_{d}$ in the above equation are the inertial and drag coefficient and is assumed as 2.0 and 1.0, respectively (Jiang 2018). Furthermore, $\dot{x}_{w}$ in the above equation describes the velocity, whereas $\ddot{x}_{w}$ describes the acceleration of water particles at the strip centre.

\section{Wind and Aerodynamic Model}

Cross-flow principles are used, which assume the wind flow as $2 \mathrm{D}$, and neglect the wind flow in the span-wise direction of 
the blade. As the blade is non-rotating, steady lift and drag coefficients are utilised (Bak et al. 2013; Verma et al. 2019b) to calculate aerodynamic loads exerted on blade sections. The Mann's turbulence (Mann 1994) module available in HAWC2 code is utilised to generate inflow turbulent field in this study. This module is defined by three parametersturbulence length scale factor, eddy lifetime and spectral multiplier. The details of these parameters can be found in Jiang et al. (2018).

\subsection{Environmental Load Cases for Time Domain Analysis}

In this study, North Sea centre is considered for studying the effect of wind-wave misalignment during offshore blade mating task. The offshore site has a water depth of $29 \mathrm{~m}$, which nears the water depth of $30 \mathrm{~m}$ considered for the monopile foundation in this study. Figure $7 \mathrm{a}$ and $\mathrm{b}$ present the histogram of $H_{s}$ and $T_{p}$, respectively, from 10 years of hindcast data (2001-2010). It can be clearly seen that bulk of $H_{s}$ for the site is less than $6 \mathrm{~m}$, whereas $T_{p}$ lies in the range of $2-16 \mathrm{~s}$.

Given that the mating task is expected to give very high responses for $H_{s}>3 \mathrm{~m}$, the present paper only

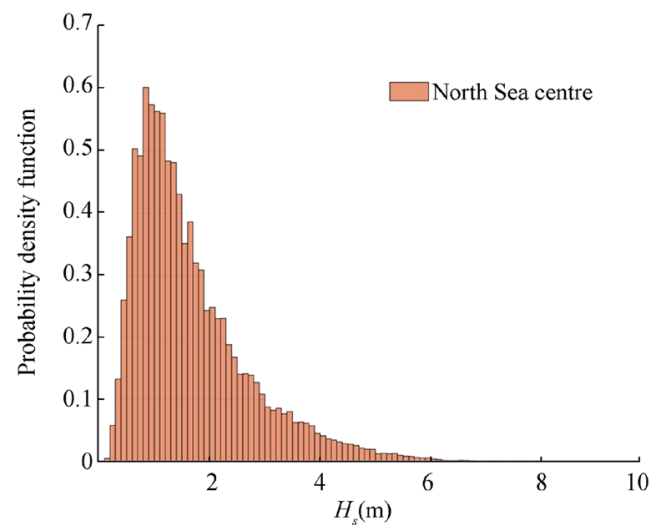

(a) $H_{s}$

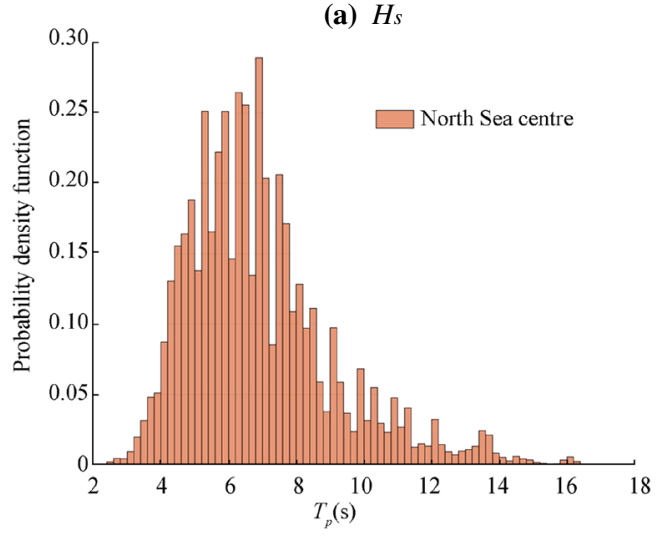

(b) $T_{p}$

Figure 7 Histogram data at North Sea centre
Table 2 Description of environmental load cases

\begin{tabular}{llllll}
\hline EC & $\beta_{\text {wave }}\left(^{\circ}\right)$ & $H_{s}(\mathrm{~m})$ & $T_{p}(\mathrm{~s})$ & $U_{w}(\mathrm{~m} / \mathrm{s})$ & $T_{I}$ \\
\hline 1 & 0 & $1,1.5, \ldots .3 .0$ & $4,6, \ldots 12$ & 10 & 0.12 \\
2 & 30 & $1,1.5, \ldots .3 .0$ & $4,6, \ldots 12$ & 10 & 0.12 \\
3 & 60 & $1,1.5, \ldots .3 .0$ & $4,6, \ldots 12$ & 10 & 0.12 \\
4 & 90 & $1,1.5, \ldots .3 .0$ & $4,6, \ldots 12$ & 10 & 0.12 \\
\hline
\end{tabular}

considers time domain analysis for $H_{S}$ in the range $1 \mathrm{~m} \leq$ $H_{s} \leq 3 \mathrm{~m}$ where $H_{s}$ varies with a step of $0.5 \mathrm{~m}$. Again, the analysis considers $T_{p}$ in the range $4 \mathrm{~s} \leq T_{p} \leq 12 \mathrm{~s}$, where $T_{p}$ varies with a step of $2 \mathrm{~s}$. Also, since the site has wind-wave misalignments varying between $0^{\circ}$ and $90^{\circ}$ (as discussed in Section 1), four cases of wind-wave misalignments $\left(\beta_{\mathrm{wave}}=0^{\circ}, 30^{\circ}, 60^{\circ}\right.$ and $\left.90^{\circ}\right)$ are considered for each load case. For simplicity, only one case of mean wind speed $\left(U_{w}=10 \mathrm{~m} / \mathrm{s}\right)$ is considered in this paper and corresponds to turbulence intensity of 0.12 selected from IEC standard (IEC 2005). Figure 8 presents the bird view of the installation process, where different wind-wave misalignments taken in the paper are illustrated. The details of environmental load cases are mentioned in Table 2.
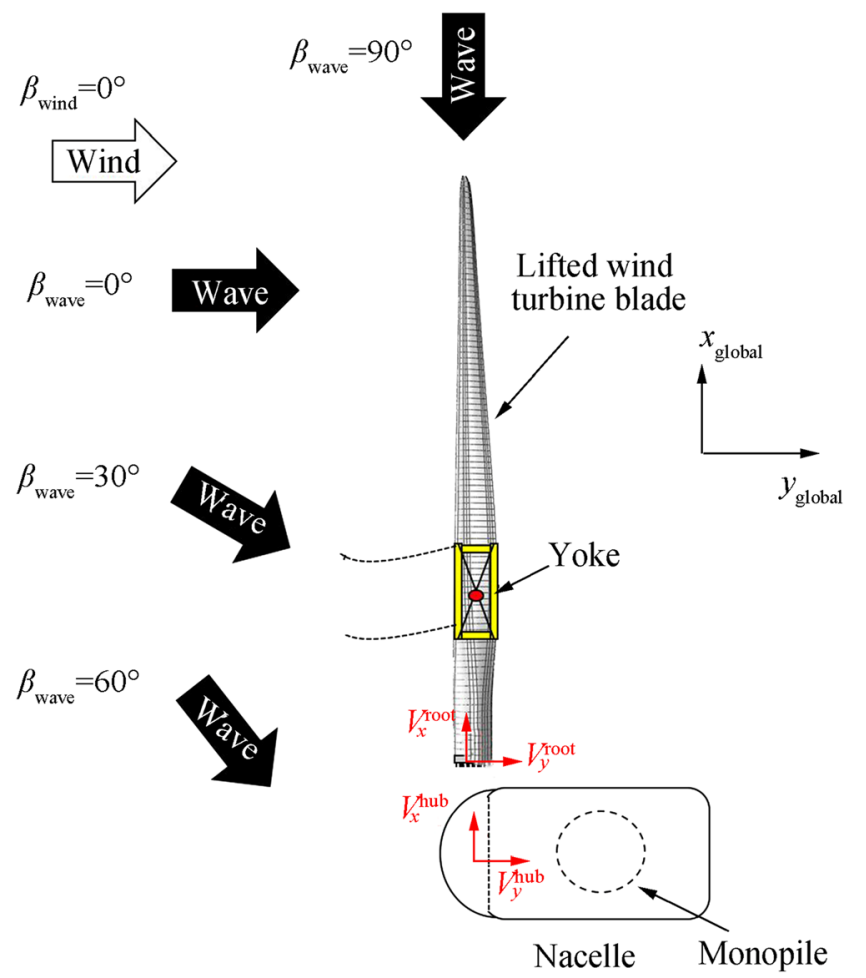

Figure 8 Bird view of mating process with considered wind-wave misalignment 


\subsection{Time Domain Analyses}

Time domain analyses are performed at a time step of $0.01 \mathrm{~s}$ with each environmental load case analysed for 20 seeds for stochastic variability. Therefore, a total sum of 2000 environmental cases are considered for the time domain analysis. Each case has a total time duration of $1000 \mathrm{~s}$, where first $400 \mathrm{~s}$ are removed during post-processing to avoid any transient effects.

\subsection{Modelling and Analysis of Blade Root Impact with Hub}

The main purpose of the impact analysis is to relate the impact velocity obtained for a given wind-wave misalignment condition with the damages obtained at the blade root. In this way, allowable impact velocities in fore-aft $\left(V_{y}^{\text {allow }}\right)$ and side-side $\left(V_{x}^{\text {allow }}\right)$ direction are obtained. Here, the details for structural modelling and analysis of blade root impact with hub are discussed for sideways and head-on impact scenarios. It is assumed that for both the scenarios, single guide pin at root suffers impact, and thus, any distribution of contact forces among adjacent bolts is neglected. It is to be noted that a detailed finite element modelling technique describing sideways' impact scenario was thoroughly presented in Verma et al. (2019a). In this study, the same model is used for head-on impact but with a different direction for impact loads, and thus, the details of finite element model are described only briefly.

Abaqus/explicit (Hibbitt et al. 2016) environment is chosen as the solver environment for impact analysis given that it is suited for non-linear problems involving large rotation, large displacements and complex interaction (Verma et al. 2019e). The DTU 10 MW blade, which is based on shell-element is considered for impact assessment.
The parent blade model has a span of $86.4 \mathrm{~m}$ with a root radius of $2.7 \mathrm{~m}$ and has no detailed connections or joint descriptions at its root (Verma et al. 2019f). For the purpose of impact assessment, a high-fidelity 3D finite element model for T-bolt connection is separately developed and is coupled with remaining region of the blade using shell-to-solid coupling constraint feature in Abaqus (Figure 9). The components of the T-bolt connectionssteel guide pin, steel barrel nut and root laminate with Triaxial layup [+45/-45/0] (see dimensions in Figure 9) -are modelled with eight noded linear brick elements with reduced integration (C3D8R) elements. The remaining region of the blade is discretised with four noded thick conventional shell (S4R) elements. The details of the element size, mesh sensitivity study and contact formulations between the components of T-bolt connection can be found in Verma et al. (2019a, 2020).

A simplified structural representation of hub is considered for impact assessment. The hub is defined as a rigid body, discretised with four noded bilinear (R3D4) elements, and is constrained in all degrees of freedom. General contact attribute together with suitable tangential and mechanical interaction properties available in Abaqus/explicit is used to define contact between impact surface of the guide pin and hub. For the case of sideways' impact, the initial impact surface is transverse to the guide pin (red arrows, Figure 9), whereas for head-on impact, the initial impact surface is along its axial direction (blue arrows, Figure 9). Maximum stress failure criterion is used as failure prediction model for root laminate, whereas von-Mises equivalent plastic strain criterion is used for damage assessment at barrel nut and guide pin. The details of these criteria along with corresponding material properties can also be found in Verma et al. (2019a, 2020).

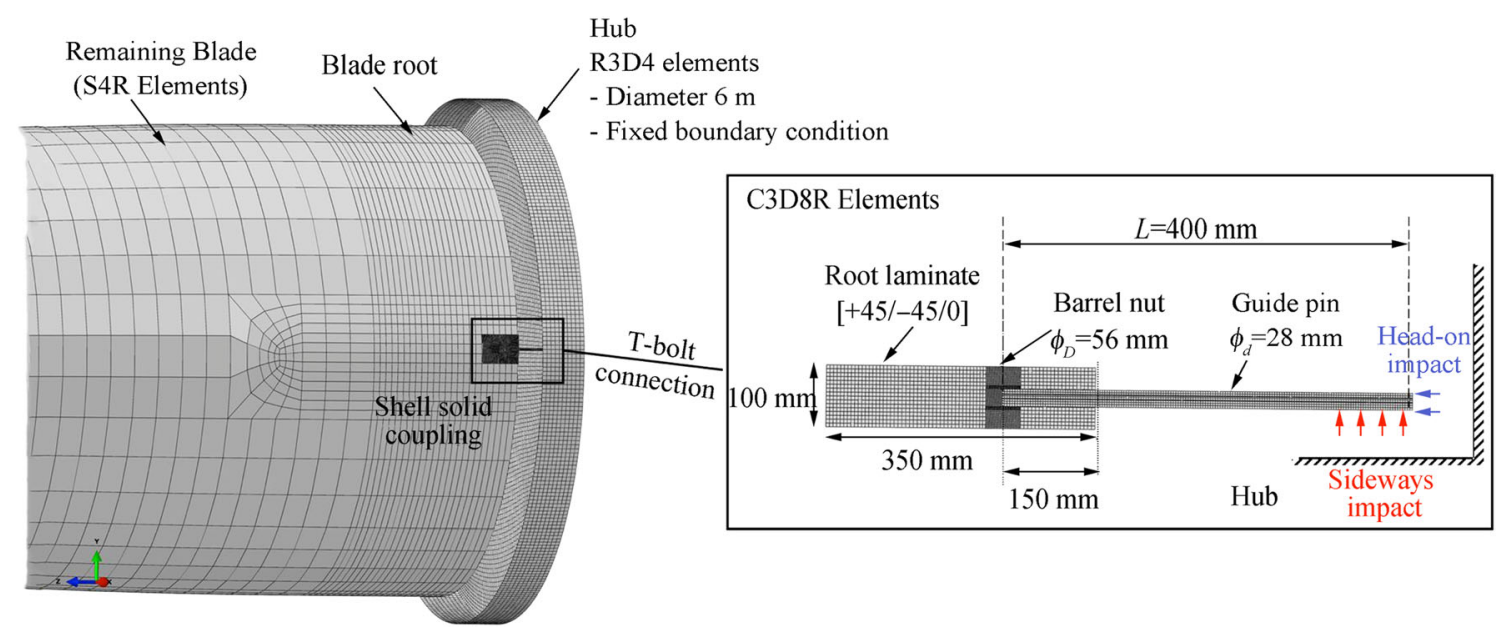

Figure 9 Finite element modelling of guide pin impact with hub for sideways and head-on impact scenarios 
It is to be noted that the structural coordinate system for finite element analysis is different from the ones used in HAWC2 simulation. The sideways' impact corresponds to initial impact velocity in $x$-direction of structural coordinate system $\left(V_{x}^{\mathrm{fem}}\right)$ whereas head-on impact represents impact velocity in $z$ -direction of structural coordinate system $\left(V_{z}^{\mathrm{fem}}\right)$. Impact velocities in the range of $0.1 \leq\left[V_{x}^{\mathrm{fem}}, V_{z}^{\mathrm{fem}}\right] \leq 2 \mathrm{~m} / \mathrm{s}$ are used for impact assessment for sideways and head-on scenarios.

\section{Results and Discussion}

In this section, response time histories, spectral densities and corresponding standard deviations are considered for discussing the effect of wind-wave misalignment on the wind turbine blade mating process. First, an individual description of hub-centre and blade root motions are presented, followed by discussion of impact velocity between root and hub for different wind-wave misalignment. Then, the damage assessment results for blade root impact with hub are discussed, where allowable impact velocities for sideways and head-on impact scenarios are estimated. Finally, a safe domain for performing mating task under different wind-wave misalignment conditions is compared.

\subsection{Hub Motions}

Figure 10a and $\mathrm{b}$ present the time histories of hub-centre displacement in side-side $\left(U_{x}^{\text {hub }}\right)$ and fore-aft ( $\left.U_{y}^{\text {hub }}\right)$ directions for mating process in an environmental condition with $H_{S}=$ $2.5 \mathrm{~m}, T_{p}=4 s, U_{w}=10 \mathrm{~m} / \mathrm{s}$ and different wind-wave misalignments $\left(\beta_{\text {wave }}=0^{\circ}, 30^{\circ}, 60^{\circ}\right.$ and $\left.90^{\circ}\right)$. It can be clearly seen that the motion of hub in side-side direction $\left(U_{x}^{\text {hub }}\right)$ is highest for largest degree of misalignment $\left(\beta_{\text {wave }}=90^{\circ}\right)$, with amplitude of responses further decreasing with shift in degree of misalignment. It is further observed that the motion of hub-centre in side-side direction $\left(U_{x}^{\text {hub }}\right)$ is negligible for load case with completely aligned wind-wave condition $\left(\beta_{\text {wave }}=0^{\circ}\right)$; see Figure 10a. On the contrary, the motion of hub-centre in fore-aft direction ( $U_{y}^{\text {hub }}$ ) is largest for load case with $\beta_{\text {wave }}$ $=0^{\circ}$ condition (see Figure 10b), and reduces with increasing degree of misalignment. For $\beta_{\text {wave }}=90^{\circ}$, the motion of hub-centre in fore-aft direction is found insignificant.

The same observation is also described through Figure 10c and d where spectral density curves for $U_{x}^{\text {hub }}$ and $U_{y}^{\text {hub }}$ are compared for $H_{s}=2.5 \mathrm{~m}, T_{p}=4 \mathrm{~s}, U_{w}=10 \mathrm{~m} / \mathrm{s}$ and different wind-wave misalignment $\left(\beta_{\mathrm{wave}}=0^{\circ}, 30^{\circ}\right.$, $60^{\circ}$ and $90^{\circ}$ ). Given that the eigen period of the monopile structure in the first fore-aft and side-side bending modes is approximately $4.25 \mathrm{~s}$, the load case with $T_{p}=4 \mathrm{~s}$ causes resonance-induced amplification of responses, and thus,
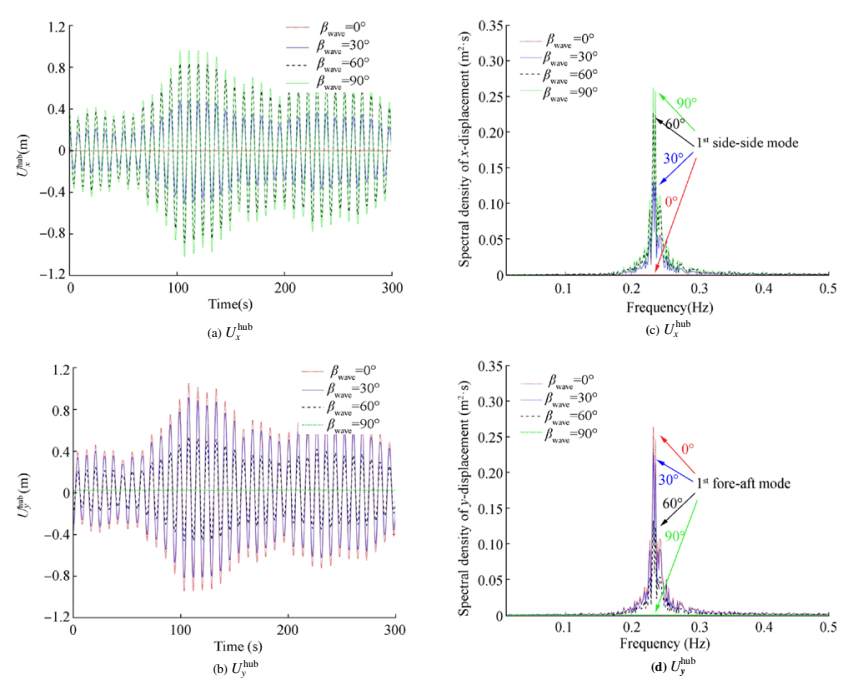

Figure 10 Response time histories and spectral density curve for load case $H_{s}=2.5 \mathrm{~m}, T_{p}=4 \mathrm{~s}, U_{w}=10 \mathrm{~m} / \mathrm{s}$ and for $\beta_{\text {wave }}=0^{\circ}, 30^{\circ}, 60^{\circ}$, and $90^{\circ}$

the highest peak of frequency is observed at approximately $0.23 \mathrm{~Hz}$. The frequency peak corresponding to the monopile's first side-side mode is maximum for largest degree of misalignment $\left(\beta_{\mathrm{wave}}=90^{\circ}\right)$, whereas the frequency peak corresponding to the monopile's first fore-aft mode is maximum for aligned wind-wave condition $\left(\beta_{\text {wave }}=0^{\circ}\right)$.

Figure 11a-b present the motion of hub-centre in $x y$-plane for mating process in different wind-wave misalignment condition $\left(\beta_{\text {wave }}=0^{\circ}, 30^{\circ}, 60^{\circ}\right.$ and $\left.90^{\circ}\right)$ and two $T_{p}\left(T_{p}=4 \mathrm{~s}\right.$ and $T_{p}=6 \mathrm{~s}$ ). As expected, for both the values of $T_{p}$, the motion of hub-centre for $\beta_{\text {wave }}=0^{\circ}$ is concentrated explicitly in fore-aft direction $\left(U_{y}^{\text {hub }}\right)$, whereas motion of hub-centre for $\beta_{\text {wave }}=$ $90^{\circ}$ is concentrated solely in side-side direction $\left(U_{x}^{\text {hub }}\right)$.
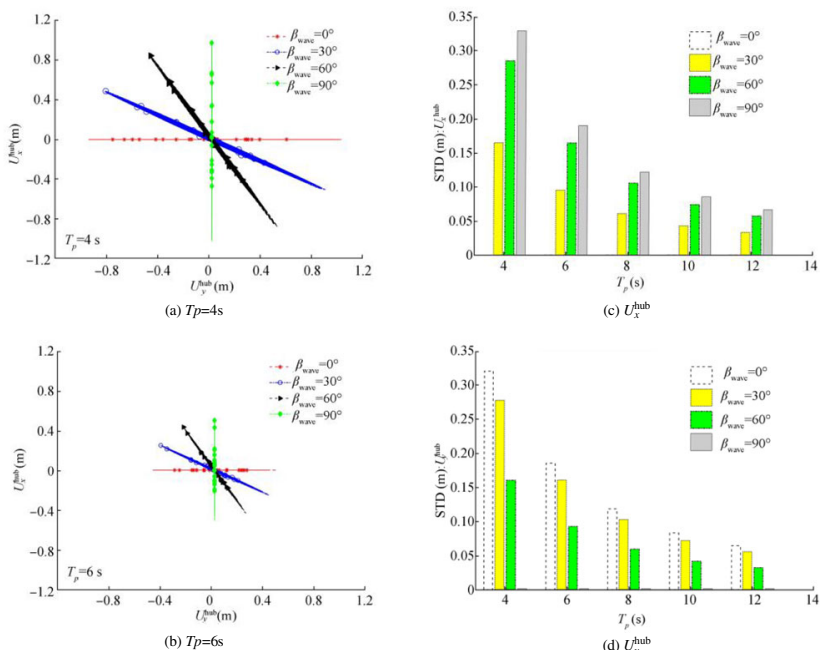

Figure 11 Motion of hub-centre in $x y$-plane and comparison of standard deviations for load case $H_{s}=2.5 \mathrm{~m}, T_{p}=4 \mathrm{~s}, 6 \mathrm{~s}, 8 \mathrm{~s}, 10 \mathrm{~s}, 12 \mathrm{~s}, U_{w}=$ $10 \mathrm{~m} / \mathrm{s}$ and $\beta_{\text {wave }}=0^{\circ}, 30^{\circ}, 60^{\circ}$ and $90^{\circ}$ 
However, it is observed that for $\beta_{\text {wave }}=30^{\circ}, 60^{\circ}$, the motions of hub-centre in fore-aft and side-side directions are correlated. It is to be also noted that the motion of hub-centre in $x y$-plane is substantially high for $T_{p}=4 \mathrm{~s}$, which nears the eigen period of the monopile structure in both side-side and fore-aft bending mode. On the other hand, for $T_{p}=6 \mathrm{~s}$, the motion of hub-centre in $x y$ plane is reduced by more than $40 \%$, given that the wave frequency is away from the excitation frequency of the monopile structure.

A comparison between the standard deviation of $U_{x}^{\text {hub }}$ and $U_{y}^{\text {hub }}$ for mating process in varying wind-wave misalignments $\left(\beta_{\text {wave }}=0^{\circ}, 30^{\circ}, 60^{\circ}\right.$ and $\left.90^{\circ}\right)$ and varying values of $T_{p}\left(T_{p}=\right.$ $4 s, 6 s, 8 s, 10 s, 12 s)$ is also presented in Figure $11 \mathrm{c}-\mathrm{d}$. It is clearly observed that the standard deviation for both $U_{x}^{\text {hub }}$ and $U_{y}^{\text {hub }}$, is highest for $T_{p}=4 \mathrm{~s}$, and further reduces with increasing values of $T_{p}$ for all degrees of misalignments. This is because of the shift in wave spectral peak period away from the eigen period of the monopile structure. Also, for a given $T_{p}$, standard deviation of $U_{x}^{\text {hub }}$ is largest for $\beta_{\text {wave }}=90^{\circ}$, and smallest for $\beta_{\text {wave }}=0^{\circ}$, whereas standard deviation of $U_{y}^{\text {hub }}$ is highest for $\beta_{\mathrm{wave}}=0^{\circ}$, and least for $\beta_{\mathrm{wave}}=90^{\circ}$.

\subsection{Blade Root Motions}

Figure 12a presents the displacement of blade root in global $x$ - and $y$-direction of the installation system for environmental condition with $U_{w}=10 \mathrm{~m} / \mathrm{s}$. The blade root responses in $y$-direction are dominant compared with its motion in $x$-direction which is negligible. This is due to the action of tugger lines which constrains the blade root motions in $x$-direction. Figure $12 \mathrm{~b}$ presents the spectral density curve for the blade root displacement in global $y$-direction, where peak frequency is observed at approximately $0.08 \mathrm{~Hz}$, and corresponds to $f_{r 1}$.

\subsection{Impact Velocity Between Blade Root and Hub}

Figure 13a-b present the impact velocity between blade root and hub in side-side ( $\left.V_{x}^{\text {imp }}\right)$ and fore-aft $\left(V_{y}^{\text {imp }}\right)$ direction for mating process in an environmental condition with $H_{s}=2.5 \mathrm{~m}$, $T_{p}=4 \mathrm{~s}, U w=10 \mathrm{~m} / \mathrm{s}$ and different wind-wave misalignments $\left(\beta_{\mathrm{wave}}=0^{\circ}, 30^{\circ}, 60^{\circ}\right.$ and $\left.90^{\circ}\right)$. It can be seen that the impact velocity in the side-side direction $\left(V_{x}^{\text {imp }}\right)$ is highest for $\beta_{\text {wave }}=$ $90^{\circ}$ with maximum response reaching a value of more than $1.5 \mathrm{~m} / \mathrm{s}$. Furthermore, the amplitude of $V_{x}^{\text {imp }}$ reduces with decrease in the degree of misalignment, with negligible response for aligned wind-wave conditions $\left(\beta_{\text {wave }}=0^{\circ}\right)$. Since impact velocity in the side-side direction $\left(V_{x}^{\text {imp }}\right)$ is dominant for large wind-wave misalignments, this implies that head-on impact scenarios can occur between blade root and hub for

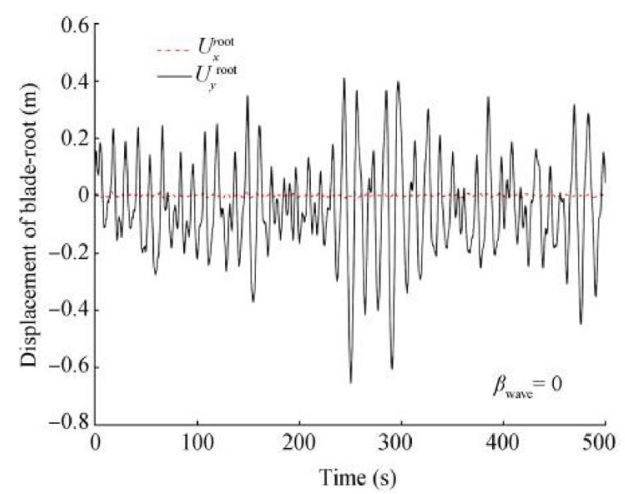

(a) Time history

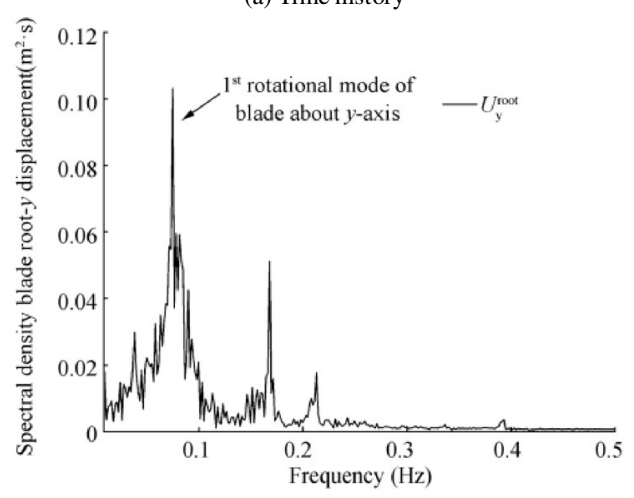

(b) Spectral density

Figure 12 Blade root responses for $U_{w}=10 \mathrm{~m} / \mathrm{s}$

such cases. On the contrary, impact velocity in the fore-aft direction $\left(V_{y}^{\mathrm{imp}}\right)$ is highest for aligned wind-wave condition $\left(\beta_{\text {wave }}=0^{\circ}\right)$, and reduces with further increase in misalignment. Therefore, aligned wind-wave condition can cause sideways impact of the blade root guide pin with the hub. Also, there are acceptable responses for $V_{y}^{\text {imp }}$ for load case with $\beta_{\text {wave }}=90^{\circ}$ because of contribution from blade root responses in the fore-aft direction.
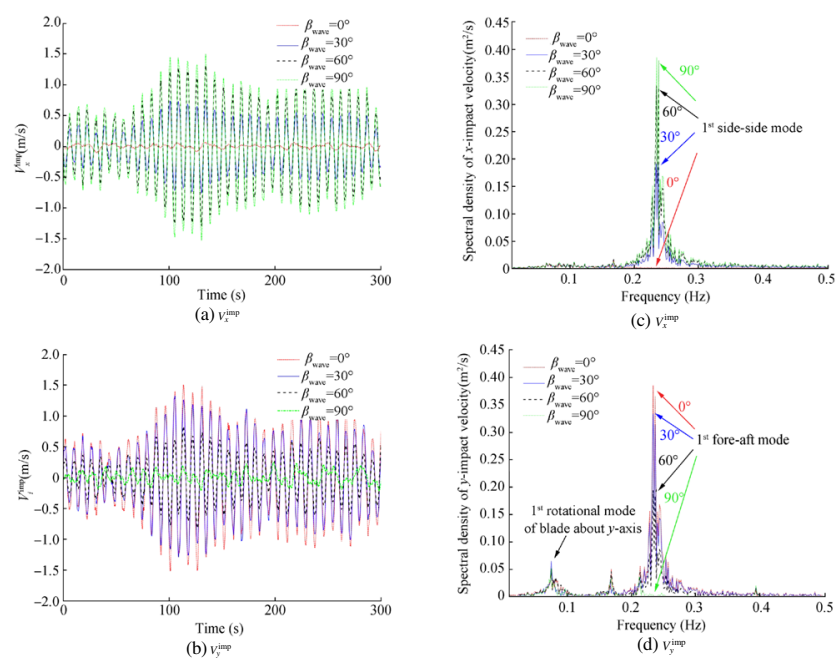

Figure 13 Response time histories and spectral density curve for load case $H_{s}=2.5 \mathrm{~m}, T_{p}=4 \mathrm{~s}, U_{w}=10 \mathrm{~m} / \mathrm{s}$ and for different wind-wave misalignment $\beta_{\text {wave }}=0^{\circ}, 30^{\circ}, 60^{\circ}$ and $90^{\circ}$ 
Figure $13 \mathrm{c}-\mathrm{d}$ present the spectral density curve for $V_{x}^{\text {imp }}$ and $V_{y}^{\text {imp }}$ for mating process in an environmental condition with $H_{s}=2.5 \mathrm{~m}, T_{p}=4 \mathrm{~s}, U w=10 \mathrm{~m} / \mathrm{s}$ and different wind-wave misalignments $\left(\beta_{\text {wave }}=0^{\circ}, 30^{\circ}, 60^{\circ}\right.$ and $\left.90^{\circ}\right)$. As observed before, the spectral density for $V_{x}^{\text {imp }}$ has highest frequency peak observed for $\beta_{\text {wave }}=90^{\circ}$, whereas spectral density for $V_{y}^{\text {imp }}$ has highest frequency peak observed for $\beta_{\text {wave }}=$ $0^{\circ}$. It can also be seen in Figure 13d that there is no contribution of hub response towards $V_{y}^{\text {imp }}$ for $\beta_{\text {wave }}=90^{\circ}$; however, there is contribution of frequency peak corresponding to the blade root responses. Note that there are two peaks observed for spectral density curves corresponding to impact velocity in fore-aft direction $\left(V_{y}^{\mathrm{imp}}\right)$. First peak corresponds to the first rotational mode of the blade about global $y$-axis $(0.08 \mathrm{~Hz})$, whereas the other peak corresponds to eigen frequency of the monopile in the first fore-aft mode $(0.23 \mathrm{~Hz})$.

On the other hand, there is only one frequency peak observed for $V_{x}^{\text {imp }}$, which corresponds to eigen frequency of monopile in first side-side mode. Here, no frequency peak is observed for blade root motions. This is because in this study, wind is considered acting from the fore-aft direction of the installation system.

Figure $14 \mathrm{a}-\mathrm{b}$ present the standard deviation of $V_{x}^{\mathrm{imp}}$ and $V_{y}^{\text {imp }}$ for mating process in an environmental condition

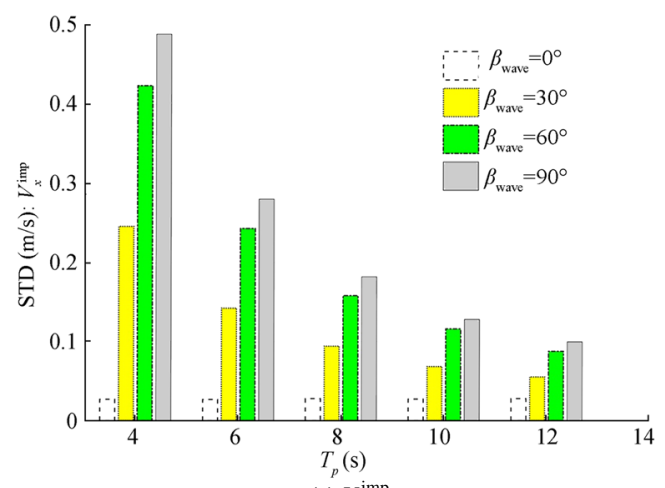

(a) $V_{x}^{\text {imp }}$

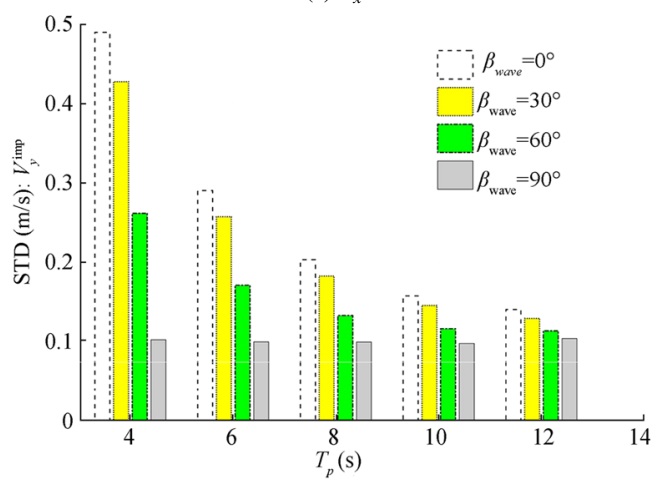

(b) $V_{y}^{\mathrm{imp}}$

Figure 14 Comparison of standard deviations for load case $H_{s}=2.5 \mathrm{~m}$, $T_{p}=4 \mathrm{~s}, 6 \mathrm{~s}, 8 \mathrm{~s}, 10 \mathrm{~s}, 12 \mathrm{~s}, U_{w}=10 \mathrm{~m} / \mathrm{s}$ and for different wind-wave misalignment $\beta_{\mathrm{wave}}=0^{\circ}, 30^{\circ}, 60^{\circ}$ and $90^{\circ}$ corresponding to $H_{s}=2.5 \mathrm{~m}, U_{w}=10 \mathrm{~m} / \mathrm{s}$, wind-wave misalignments $\left(\beta_{\mathrm{wave}}=0^{\circ}, 30^{\circ}, 60^{\circ}\right.$ and $\left.90^{\circ}\right)$ and varying values of $T_{p}$ $\left(T_{p}=4 \mathrm{~s}, 6 \mathrm{~s}, 8 \mathrm{~s}, 10 \mathrm{~s}, 12 \mathrm{~s}\right)$. It is seen that the standard deviation for both $V_{x}^{\mathrm{imp}}$ and $V_{y}^{\mathrm{imp}}$ reduces with increasing values of $T_{p}$, with highest standard deviation obtained for $T_{p}=4 \mathrm{~s}$. Also, for a given $T_{p}$, standard deviation for $V_{x}^{\text {imp }}$ is highest for $\beta_{\text {wave }}=90^{\circ}$, whereas standard deviation for $V_{y}^{\text {imp }}$ is largest for $\beta_{\text {wave }}=0^{\circ}$. Furthermore, as discussed, there are acceptable responses for $V_{y}^{\text {imp }}$ for $\beta_{\text {wave }}=90^{\circ}$ and have the same standard deviations for all values of $T_{p}$. This is because there is no contribution of hub responses for $\beta_{\text {wave }}=90^{\circ}$, and all results correspond to the blade root responses at $U_{w}=10 \mathrm{~m} / \mathrm{s}$. Therefore, for $\beta_{\text {wave }}=90^{\circ}$, $V_{y}^{\text {imp }}$ is completely dominated by blade root motions.

\subsection{Damage Assessment at the Blade Root}

In this section, allowable impact velocities are evaluated for head-on $\left(V_{x}^{\text {allow }}\right)$, and sideways ( $\left.V_{y}^{\text {allow }}\right)$ impact scenarios, based on which structural safety assessment of mating task will be performed for different sea states. Impact velocities in the range of $0.1 \mathrm{~m} / \mathrm{s} \leq\left[V_{x}^{\mathrm{fem}}, V_{z}^{\mathrm{fem}}\right] \leq 2 \mathrm{~m} / \mathrm{s}$ are considered for impact assessment. Figure $15 \mathrm{a}-\mathrm{b}$ present $I_{f}^{z}\left(S_{33}\right)$ obtained

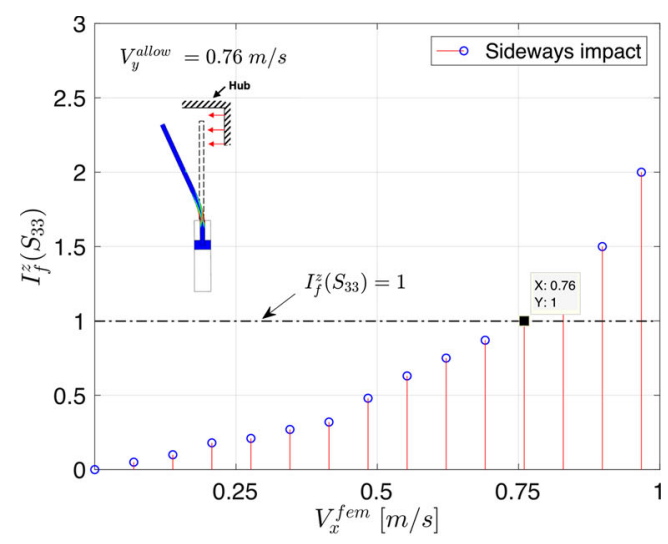

(a) Sideways impact $\left(V_{y}^{\text {allow }}=0.76 \mathrm{~m} / \mathrm{s}\right)$

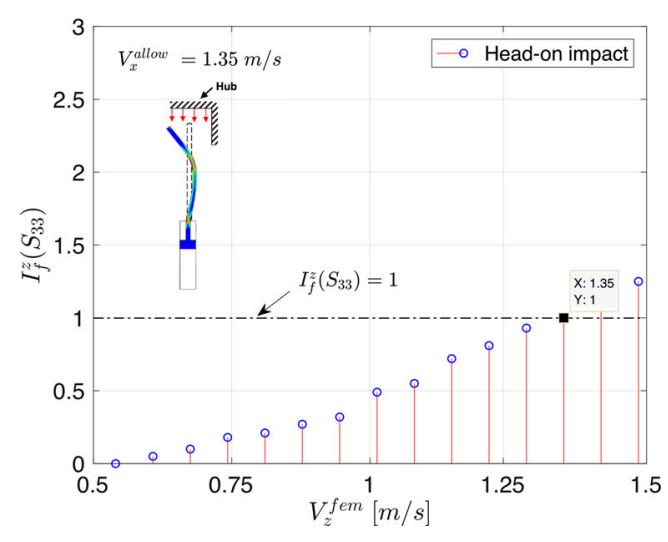

(b) Head-on impact $\left(V_{x}^{\text {allow }}=1.35 \mathrm{~m} / \mathrm{s}\right)$

Figure 15 Allowable impact velocities 
for different impact velocities corresponding to sideways and head-on impact scenarios, respectively. It can be seen that for sideways scenario, impact velocity above $0.76 \mathrm{~m} / \mathrm{s}$ causes $I_{f}^{z}$ $(S 33) \geq 1$, and thus, $0.76 \mathrm{~m} / \mathrm{s}$ is considered as allowable impact velocity in fore-aft direction $\left(V_{y}^{\text {allow }}=0.76 \mathrm{~m} / \mathrm{s}\right)$. On the other hand, for head-on impact scenario, impact velocity above $1.35 \mathrm{~m} / \mathrm{s}$ causes $I_{f}^{z}\left(S_{33}\right) \geq 1$, and thus, $1.35 \mathrm{~m} / \mathrm{s}$ is considered as allowable impact velocity in side-side direction $\left(V_{x}^{\text {allow }}=1.35 \mathrm{~m} / \mathrm{s}\right)$. This clearly implies that the sideways' impact scenario, developed largely due to aligned wind-wave condition, is more critical compared with head-on impact scenarios, given that failure in the root laminate is achieved at relatively less impact velocity. The reason for this is that sideways' impact scenario involves impact loads along the transverse direction of the guide pin (see Figure 15a), causing its inelastic bending at low impact velocity. On the other hand, for the case of head-on impact, impact loads are caused in the axial direction of guide pin bolt (see Figure 15b), where the bolt has high strength and stiffness, and are designed to take operational loads.

Furthermore, failure mode consists of s-shape buckling of guide pin, and the failure in the laminate is developed at a large impact velocity. A comparison of the failure modes obtained at the blade root for sideways and head-on impact scenarios above the threshold level is presented in Figure 16. Here, the results for sideways' impact correspond to $V_{x}^{\text {fem }}=0.85 \mathrm{~m} / \mathrm{s}$, and head-on impact corresponds to $V_{z}^{\mathrm{fem}}=1.45 \mathrm{~m} / \mathrm{s}$.

It can be clearly seen that the impact of the blade root in the sideways direction causes bending of guide pin with an angle of approximately $12^{\circ}$. On the contrary, impact in the head-on direction causes s-shape buckling of guide pin. Furthermore, due to these failure modes in the form of inelastic deformation, guide pin impacts the root laminate near the inplane hole for both the scenarios, and thus, transverse through-the-thickness normal tensile stresses are induced at the critical location $z$ of the blade root. These are represented by stress exposure factors coloured in white fringes and correspond to failure index at location $z$ more than $1\left(I_{f}^{z}\left(S_{33}\right)>1\right)$. Also, note that the stress exposure factors corresponding to transverse through-the-thickness compressive stresses $\left(I_{f}^{z}\left(S_{33}\right)<0\right.$ ) are also developed near the inplane hole, however are not comparatively that critical for development of delamination at this region. Furthermore, these stresses are developed in two different and opposite corners of the inplane hole, for sideways and head-on impact scenarios. The reason for this is that for sideways' impact scenarios, guide pin impacts the inplane hole along the direction of the bend, whereas for head-on impact, guide pin deforms in s-shape and impacts the inplane hole in the direction of its buckled curvature.

\subsection{Structural Safety Assessment of Mating Task for Sea States with Given Wind-Wave Misalignment}

In this section, structural safety assessment of blade mating task will be assessed for load cases with different wind-wave misalignment conditions and corresponding safe domain for the installation task will be compared. First, extreme value distributions and corresponding characteristic extreme responses are obtained for impact velocities in fore-aft and side-side direction. Then, these characteristic values are compared with their allowable impact velocities, and only those sea states are considered safe for mating task for which the characteristic values are less than the allowable responses.

Figure $17 \mathrm{a}-\mathrm{b}$ present the Gumbel fitting of extreme responses for impact velocities in side-side $\left(V_{x}^{\mathrm{imp}}\right)$ and fore-aft direction ( $\left.V_{y}^{\text {imp }}\right)$, respectively, for load cases with $H_{s}=2.5 \mathrm{~m}, T_{p}=4 \mathrm{~s}, U w$ $=10 \mathrm{~m} / \mathrm{s}$ and different wind-wave misalignments $\left(\beta_{\text {wave }}=0^{\circ}\right.$, $30^{\circ}, 60^{\circ}$ and $\left.90^{\circ}\right)$. Each load case consists of 20 seeds, where maximum values are extracted from the time series of impact velocities and are plotted in the Gumbel probability paper. Overall, there are 20 data points used for each load case.

It can be clearly seen that the data points describing the extreme values of $V_{x}^{\mathrm{imp}}$ and $V_{y}^{\mathrm{imp}}$ fit the Gumbel plot satisfactorily for all the load cases. It is worth mentioning that the data points were also fitted to probability papers of other distributions such as Lognormal, Weibull and Exponential to check the best fit. It was found that Gumbel distribution provides the best coefficient of determination $\left(R^{2}\right)$ and least standard error (SE).

Furthermore, the parameters $\mu$ and $\beta$, which describe the Gumbel distribution, are estimated and are explicitly mentioned next to the fitted line for load cases with different wind-wave misalignment (see Figure 17a and b) together with the corresponding $R^{2}$ and $S E$ values. Note that the cumulative distribution function of Gumbel distribution is given by $\left(F\left(V^{\mathrm{imp}}\right)=\exp \right.$ $\left.\left(-\exp \left(-\left(V^{\mathrm{imp}}-\mu\right) / \beta\right)\right)\right)$ where $\mu$ and $\beta$ are location and scale parameters, respectively. It can also be observed that the location parameter $(\mu)$ for $V_{x}^{\text {imp }}$ is largest for $\beta_{\text {wave }}=90^{\circ}$ and reduces further with reduction in degree of misalignment. On the other hand, location parameter $(\mu)$ for $V_{y}^{\text {imp }}$ is largest for $\beta_{\text {wave }}$ $=0^{\circ}$ and reduces with increase in misalignment. Similar Gumbel fitting of extreme responses and corresponding Gumbel parameters for $V_{x}^{\text {imp }}$ and $V_{y}^{\text {imp }}$ were estimated for every environment conditions examined in the present study.

Extreme value distributions for $V_{x}^{\mathrm{imp}}$ and $V_{y}^{\mathrm{imp}}$ are described using the values of the estimated parameters $(\mu$ and $\beta)$ in Figure $17 \mathrm{c}$ and d, respectively, for load cases with $H_{s}=$ $2.5 \mathrm{~m}, T_{p}=4 \mathrm{~s}, U w=10 \mathrm{~m} / \mathrm{s}$ and different wind-wave misalignments $\left(\beta_{\text {wave }}=0^{\circ}, 30^{\circ}, 60^{\circ}\right.$ and $\left.90^{\circ}\right)$. It is clearly observed that the extreme value distribution for $V_{x}^{\text {imp }}$ on the rightmost side corresponds to the load case with $\beta_{\text {wave }}=90^{\circ}$, whereas the distribution on the leftmost side corresponds to $\beta_{\text {wave }}=0^{\circ}$. 


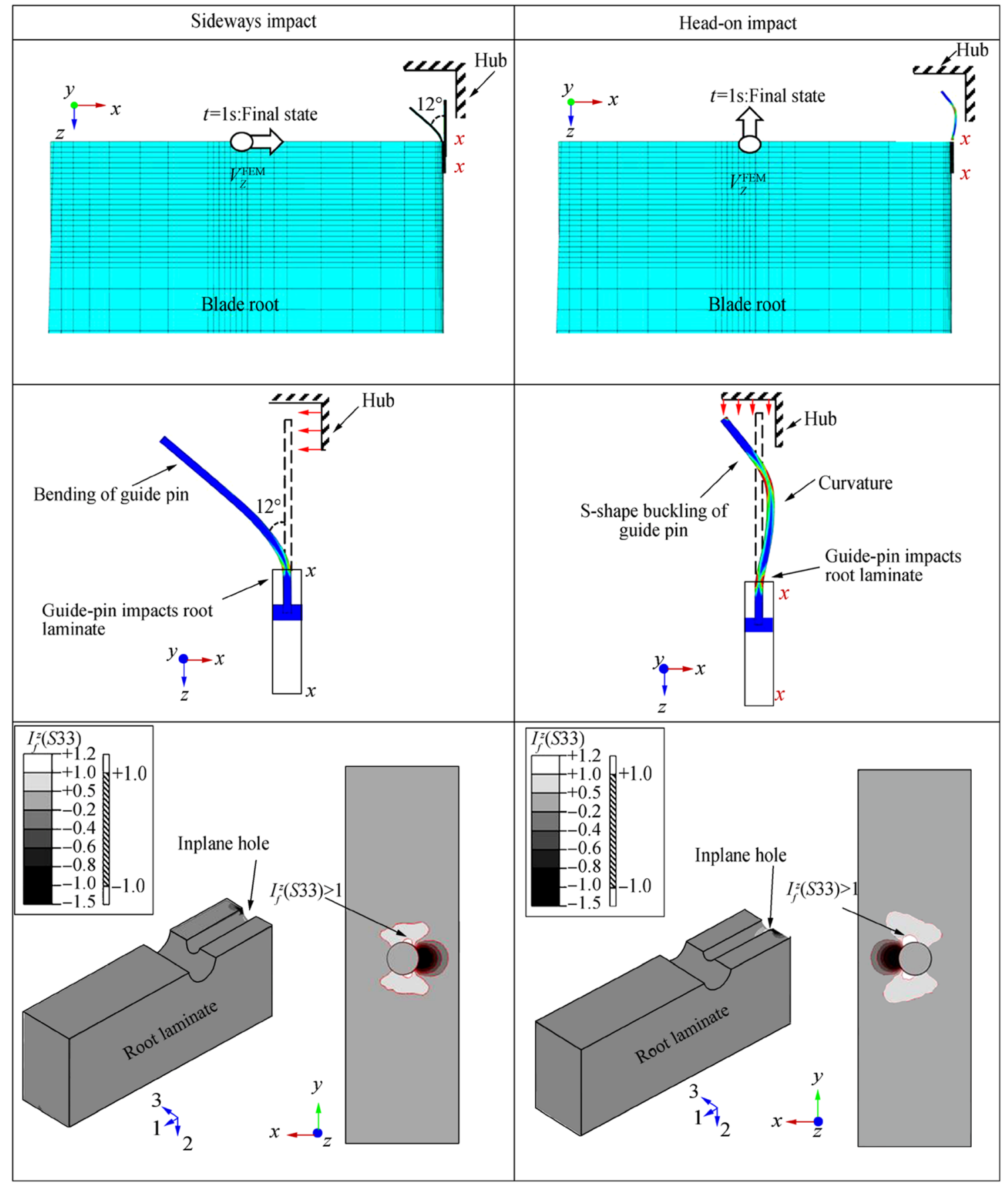

Figure 16 Comparison of failure modes for impact in sideways and head-on impact scenarios

This result is in line with the previous observations where impact velocity in the side-side direction was found largest for misaligned wind-wave conditions. Similarly, extreme value distribution for $V_{y}^{\text {imp }}$ is located on the rightmost side for aligned wind-wave condition $\left(\beta_{\text {wave }}=0^{\circ}\right)$.

Figure $18 \mathrm{a}-\mathrm{b}$ present the characteristic extreme responses for impact velocities in side-side $\left(V_{x}^{\text {char }}\right)$ and fore-aft directions $\left(V_{y}^{\text {char }}\right)$, respectively, for load cases with $H_{s}=2.5 \mathrm{~m}, T_{p}=6 \mathrm{~s}$, $U_{w}=10 \mathrm{~m} / \mathrm{s}$ and different wind-wave misalignments $\left(\beta_{\text {wave }}=\right.$ $0^{\circ}, 30^{\circ}, 60^{\circ}$ and $90^{\circ}$ ). These values are obtained using extreme value distributions and correspond to a target exceedance level of $10^{-2}$. Note that a black-dotted line is also presented in the figures to represent $10^{-2}$ exceedance level, and the point where it intersects the curve corresponds to the characteristic extreme responses for different load cases. It can be seen that $V_{x}^{\text {char }}$ is largest for $\beta_{\text {wave }}=90^{\circ}$, with the value reaching approximately $1.30 \mathrm{~m} / \mathrm{s}$. Furthermore, this value decreases with shift in the degree of misalignment and is lowest for $\beta_{\text {wave }}=0^{\circ}$. 

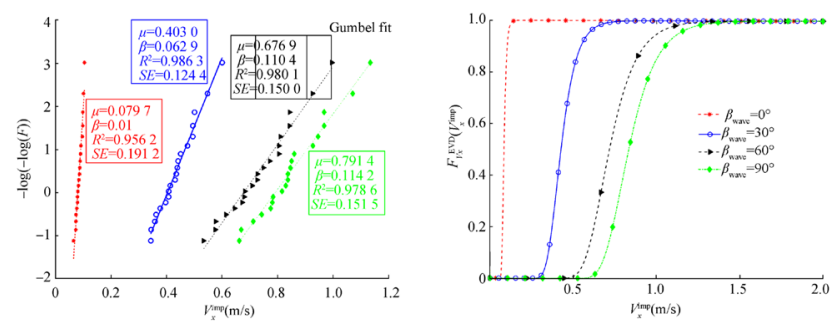

(a) $V_{x}^{\text {in }}$
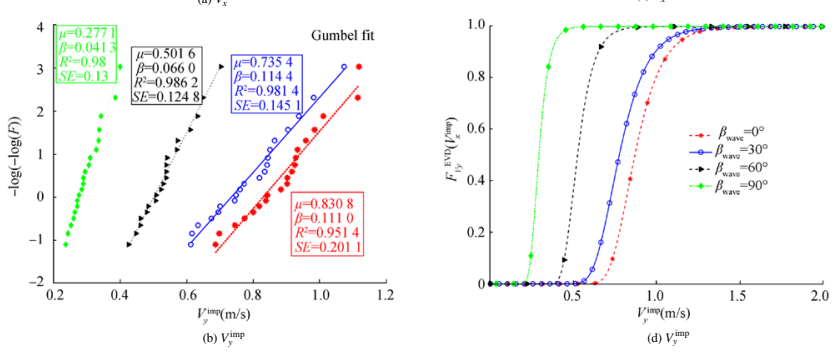

Figure 17 Gumbel fitting of extreme responses and corresponding extreme value distribution for load case $H_{s}=2.5 \mathrm{~m}, T_{p}=4 \mathrm{~s}, U_{w}=$ $10 \mathrm{~m} / \mathrm{s}$ and $\beta_{\text {wave }}=0^{\circ}, 30^{\circ}, 60^{\circ}$ and $90^{\circ}$

On the contrary, $V_{y}^{\text {char }}$ is highest for $\beta_{\text {wave }}=0^{\circ}$ and least for $\beta_{\text {wave }}=90^{\circ}$. Similar results are obtained in Figure $18 \mathrm{c}-\mathrm{d}$, where $V_{x}^{\text {char }}$ and $V_{y}^{\text {char }}$ are evaluated for load case with $H_{s}=$ $2.5 \mathrm{~m}, U_{w}=10 \mathrm{~m} / \mathrm{s}$, different wind-wave misalignments $\left(\beta_{\text {wave }}\right.$ $=0^{\circ}, 30^{\circ}, 60^{\circ}$ and $90^{\circ}$ ) and with $T_{p}=8 \mathrm{~s}$.

Finally, in order to decide whether the sea state with a given wind-wave misalignment is safe or not for mating task, it is required to compare the characteristic extreme responses in both side-side and fore-aft directions with allowable impact velocities. Only those sea states are considered safe for which $V_{x}^{\text {char }}$ and $V_{y}^{\text {char }}$ are less than their corresponding impact velocities. The $V_{x}^{\text {char }}$ and $V_{y}^{\text {char }}$ presented in Figure $18 \mathrm{a}-\mathrm{b}$ for the
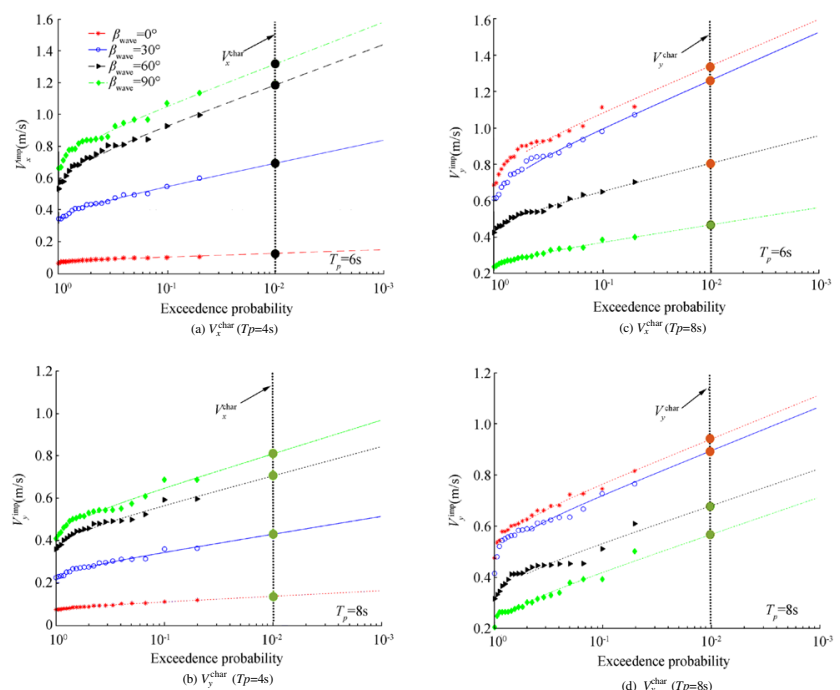

Figure 18 Characteristic extreme responses for load case: $H_{s}=2.5 \mathrm{~m}$, $U_{w}=10 \mathrm{~m} / \mathrm{s}$ and for $\beta_{\mathrm{wave}}=0^{\circ}, 30^{\circ}, 60^{\circ}$ and $90^{\circ}$ load case with $H_{s}=2.5 \mathrm{~m}, T_{p}=6 \mathrm{~s}, U w=10 \mathrm{~m} / \mathrm{s}$ and different wind-wave misalignments $\left(\beta_{\text {wave }}=0^{\circ}, 30^{\circ}, 60^{\circ}\right.$ and $\left.90^{\circ}\right)$ are compared with corresponding $V_{x}^{\text {allow }}=1.35 \mathrm{~m} / \mathrm{s}$ and $V_{y}^{\text {allow }}=0.76 \mathrm{~m} / \mathrm{s}$, respectively. Note that the characteristic extreme responses for which the values are less than the allowable responses are marked as green dots (on the dotted black line), and for those in which the characteristic responses are larger than allowable values are marked as red dots (Figure 18a-b).

It can be seen that for the case of $V_{x}^{\text {char }}$, all load cases with wind-wave misalignments are marked as green dots, given that the characteristic responses for all the misalignments are less than $V_{x}^{\text {allow }}=1.35 \mathrm{~m} / \mathrm{s}$. However, for $V_{y}^{\text {char }}$, only the load case with $\beta_{\text {wave }}=90^{\circ}$ is marked as a green dot as the characteristic responses are less than $V_{y}^{\text {allow }}=0.76 \mathrm{~m} / \mathrm{s}$. The characteristic responses corresponding to $\beta_{\text {wave }}=0^{\circ}, 30^{\circ}, 60^{\circ}$ are larger than $V_{y}^{\text {allow }}=0.76 \mathrm{~m} / \mathrm{s}$ and are hence marked as red dots. This implies that for the load case $H_{s}=2.5 \mathrm{~m}, T_{p}=6 \mathrm{~s}, U w=10 \mathrm{~m} / \mathrm{s}$, only $\beta_{\text {wave }}=90^{\circ}$ belongs to the safe domain of sea state for the mating task. Also, Figure $18 \mathrm{c}-\mathrm{d}$ show the similar comparison for the load case with $T_{p}=8 s$, and it is found that for the case of $V_{x}^{\text {char }}$, all misalignments are marked as green dots but for $V_{y}^{\text {char }}$, only $\beta_{\text {wave }}=60^{\circ}, 90^{\circ}$ are marked as green dots. Note that only those sea states are considered safe for which both $V_{x}^{\text {char }}$ and $V_{y}^{\text {char }}$ are less than $V_{x}^{\text {allow }}$ and $V_{y}^{\text {allow }}$, respectively. Therefore, for the load case $H_{s}=2.5 \mathrm{~m}, T_{p}=8 \mathrm{~s}, U w=10 \mathrm{~m} / \mathrm{s}$, only $\beta_{\text {wave }}=60^{\circ}$ and $90^{\circ}$ belong to the safe domain.

Similar calculation for safety assessment is performed for all the load cases considered in this paper, i.e. $H_{S}$ in the range $1 \mathrm{~m} \leq H_{s} \leq 3 \mathrm{~m}, T_{p}$ in the range $4 \mathrm{~s} \leq T_{p} \leq 12 \mathrm{~s}, U_{w}=$ $10 \mathrm{~m} / \mathrm{s}$ and different wind-wave misalignments $\left(\beta_{\text {wave }}=\right.$ $0^{\circ}, 30^{\circ}, 60^{\circ}$ and $90^{\circ}$ ). Figure 19 presents the comparison between different safe domains analysed for considered

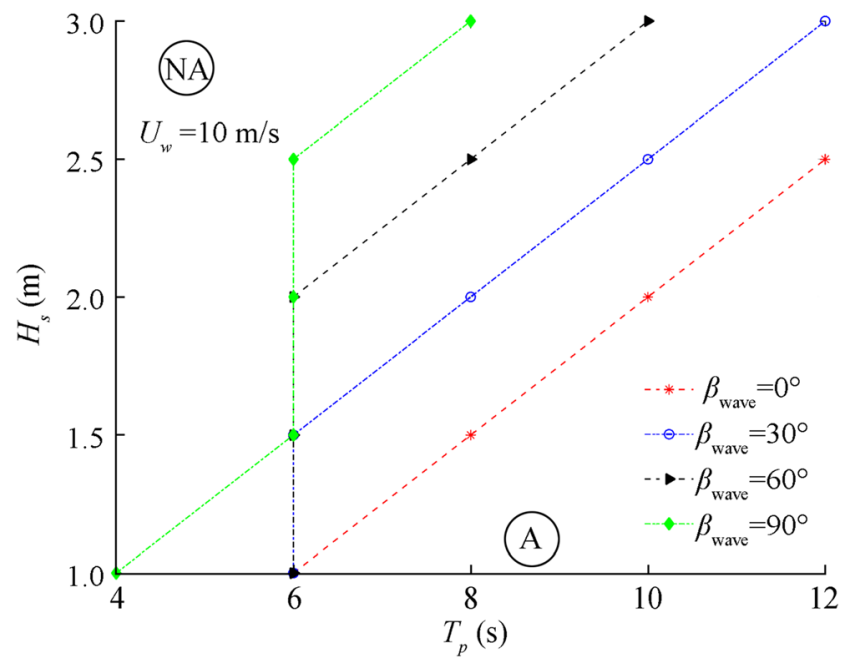

Figure 19 Comparison of safe domain for different wind-wave misalignment 
wind-wave misalignments. Note that the area lying below the line corresponding to a particular wind-wave misalignment is considered safe for the mating task. It can be clearly seen that the collinear wind-wave condition has the least percentage of safe domain, whereas $\beta_{\text {wave }}=90^{\circ}$ has highest percentage of safe sea states for the mating task. This is because of the fact that aligned wind-wave conditions cause sideways' impact that are critical and cause damages to the root laminate at relatively less impact velocity. Overall, it can be said that, although both, aligned and misaligned wind-wave conditions can induce large responses between root and hub during the blade mating process; it is the aligned wind-wave conditions that are the most critical as far as the structural safety of the blade root mating process is concerned.

\section{Conclusion}

The present paper investigated the effects of wind-wave misalignment on the wind turbine blade mating process. Three distinct response parameters: (1) impact velocity between root and hub during mating, (2) impact-induced damages at the blade root and (3) safety assessment of the mating task for a given wind-wave misalignment condition, were considered for discussion. The mating process was numerically modelled in HAWC2 numerical code, and time domain analyses were performed for load cases representing environmental conditions for the North Sea centre. Four cases of wind-wave misalignments $\left(\beta_{\text {wave }}=0^{\circ}, 30^{\circ}, 60^{\circ}\right.$ and $\left.90^{\circ}\right)$ were considered for each load case. Additionally, the impact scenarios - sideways and head-on impact of the guide pin with the hub-were also numerically modelled using Abaqus/explicit, and corresponding allowable impact velocities in the fore-aft and side-side directions were obtained. The following are the main conclusions from this study:

1) The displacement of the hub-centre in the side-side mode $\left(U_{x}^{\text {hub }}\right)$ is highest for load cases with largest wind-wave misalignment $\left(\beta_{\mathrm{wave}}=90^{\circ}\right)$, and it further reduces with shift in the degree of misalignment. On the other hand, displacement of the hub-centre in the fore-aft direction $\left(U_{y}^{\text {hub }}\right)$ is largest for aligned wind-wave cases $\left(\beta_{\text {wave }}=\right.$ $0^{\circ}$ ), and the amplitude of responses reduces with increase in misalignment.

2) The load cases with largest degree of wind-wave misalignment have the largest impact velocity in the side-side direction, and thus for such cases, head-on impact between guide pin and hub are dominant. On the contrary, aligned wind-wave cases induce largest impact velocity in the fore-aft direction, and thus cause impact of the guide pin with the hub in sideways scenario.
3) The sideways' impact of the guide pin with hub is more critical than the head-on impact, and the failure criteria in the root laminate are met at a relatively low velocity of impact. This is because sideways' impact scenario involves impact loads along the transverse direction of the guide pin causing bending of the bolt. On the other hand, for the case of head-on impact, impact loads are caused in the axial direction of guide pin, where the bolt has high strength and stiffness. This causes impact-induced buckling of guide pin, but at a large impact energy. Therefore, impact scenarios for aligned wind-wave conditions are more critical for the wind turbine blade mating process.

4) The safety assessment of the mating task was also compared for load cases with different wind-wave misalignment conditions. It was found that $\beta_{\mathrm{wave}}=90^{\circ}$ has the largest domain for safe installation of wind turbine blades, which reduces with shift in the degree of misalignment. Also, for collinear wind-wave condition $\left(\beta_{\text {wave }}=0^{\circ}\right)$, lowest percentage of safe domain for mating task was obtained. The reason for this is that aligned wind-wave conditions cause sideways impact, which, from a structural perspective, is more critical than a head-on impact scenario, developed due to misaligned wind-wave conditions.

Funding Information The study is a part of SFI MOVE projects funded by the Research Council of Norway, NFR project number 237929.

Open Access This article is licensed under a Creative Commons Attribution 4.0 International License, which permits use, sharing, adaptation, distribution and reproduction in any medium or format, as long as you give appropriate credit to the original author(s) and the source, provide a link to the Creative Commons licence, and indicate if changes were made. The images or other third party material in this article are included in the article's Creative Commons licence, unless indicated otherwise in a credit line to the material. If material is not included in the article's Creative Commons licence and your intended use is not permitted by statutory regulation or exceeds the permitted use, you will need to obtain permission directly from the copyright holder. To view a copy of this licence, visit http://creativecommons.org/licenses/by/4.0/.

\section{References}

Bachynski EE, Kvittem MI, Luan C, Moan T (2014) Wind-wave misalignment effects on floating wind turbines: motions and tower load effects. Journal of Offshore Mechanics and Arctic Engineering 136 (4):041902. https://doi.org/10.1115/1.4028028

Bak C, Zahle F, Bitsche R, Kim T, Yde A, Henriksen LC, Hansen MH, Natarajan A (2013) Description of the DTU 10 MW reference wind turbine, Progress report, Report-I-0092, DTU Wind Energy

Barj L, Jonkman JM, Robertson A, Stewart GM, Lackner MA, Haid L, Matha D, Stewart SW (2014) Wind/wave misalignment in the loads analysis of a floating offshore wind turbine, in: 32nd ASME Wind Energy Symposium: 0363. https://doi.org/10.2514/6.2014-0363

Brøndsted P, Nijssen RP (2013) Advances in wind turbine blade design and materials. Elsevier 
Fischer T, Rainey P, Bossanyi E, Kuhn M (2011) Study on control concepts suitable for mitigation of loads from misaligned wind and waves on offshore wind turbines supported on monopiles. Wind Eng 35(5):561-573. https://doi.org/10.1260/0309-524X.35.5.561

Hibbitt H, Karlsson B, Sorensen P (2016) Abaqus analysis users' manual

IEC (2005) International standard 61400-1, wind turbines, part 1: design requirements

Jiang Z (2018) The impact of a passive tuned mass damper on offshore single-blade installation. J Wind Eng Ind Aerodyn 176:65-77. https://doi.org/10.1016/j.jweia.2018.03.008

Jiang Z, Gao Z, Ren Z, Li Y, Duan L (2018) A parametric study on the blade final installation process for monopile wind turbines under rough environmental conditions. Eng Struct 172:1042-1056. https://doi.org/10.1016/j.engstruct.2018.04.078

Ketele S (2013) Detailed modeling of connections in large composite wind turbine blades. Master's thesis, Universiteit Gent

Larsen TJ, Hansen AM (2007) How 2 HAWC2, the user's manual, Tech. rep., Risø National Laboratory

Li L, Gao Z, Moan T (2015) Joint distribution of environmental condition at five European offshore sites for design of combined wind and wave energy devices. Journal of Offshore Mechanics and Arctic Engineering 137(3):031901. https://doi.org/10.1115/1.4029842

Mann J (1994) The spatial structure of neutral atmospheric surface-layer turbulence. J Fluid Mech 273:141-168. https://doi.org/10.1017/ S0022112094001886

Martınez V, Guemes A, Trias D, Blanco N (2011) Numerical and experimental analysis of stresses and failure in t-bolt joints. Compos Struct 93(10):2636-2645. https://doi.org/10.1016/j.compstruct. 2011.04.031

Molla IG (2015) Installing a blade in a wind turbine and wind turbines, US Patent App. 14/657,307

Morison J, Johnson J, Schaaf S et al (1950) The force exerted by surface waves on piles. J Pet Technol 2(05):149-154. https://doi.org/10. 2118/950149-G

Ren Z, Jiang Z, Skjetne R, Gao Z (2018a) Development and application of a simulator for offshore wind turbine blades installation. Ocean Eng 166:380-395. https://doi.org/10.1016/j.oceaneng.2018.05.011

Ren Z, Skjetne R, Gao Z et al (2018b) A crane overload protection controller for blade lifting operation based on model predictive control. Energies 12(1):1-22. https://doi.org/10.3390/en12010050

Ren Z, Skjetne R, Jiang Z, Gao Z, Verma AS (2019) Integrated GNSS/ IMU hub motion estimator for offshore wind turbine blade installation. Mech Syst Signal Process 123:222-243. https://doi.org/10. 1016/j.ymssp.2019.01.008

Van Vledder GP (2013) On wind-wave misalignment, directional spreading and wave loads, in: ASME 2013 32nd International Conference on Ocean, Offshore and Arctic Engineering, American Society of Mechanical Engineers: V005T06A087-V005T06A087. https://doi. org/10.1115/OMAE2013-11393

Velarde J (2016) Design of monopile foundations to support the DTU $10 \mathrm{MW}$ offshore wind turbine, Master's thesis, Norwegian University of Science and Technology (NTNU), Trondheim
Verma AS, Vedvik NP and Gao Z (2017) December. Numerical assessment of wind turbine blade damage due to contact/impact with tower during installation. In IOP Conference Series: Materials Science and Engineering. 276(1):012-025 https://doi.org/10.1088/1757-899X/ 276/1/012025

Verma AS, Jiang Z, Vedvik NP, Gao Z, Ren Z (2019a) Impact assessment of a wind turbine blade root during an offshore mating process. Eng Struct 180:205-222. https://doi.org/10.1016/j.engstruct.2018. 11.012

Verma AS, Vedvik NP, Gao Z (2019b) A comprehensive numerical investigation of the impact behaviour of an offshore wind turbine blade due to impact loads during installation. Ocean Eng 172:127145. https://doi.org/10.1016/j.oceaneng.2018.11.021

Verma AS, Gao Z, Jiang Z, Zhengru R, Vedvik NP (2019c) Structural safety assessment of marine operations from a long term perspective: a case study of offshore wind turbine blade installation, 38th International Conference on Ocean, Offshore and Arctic Engineering OMAE https://doi.org/10.1115/OMAE2019-96686

Verma AS, Jiang Z, Ren Z, Gao Z, Vedvik NP (2019d) Response-based assessment of operational limits for mating blades on monopile-type offshore wind turbines. Energies 12(10):1867. https://doi.org/10. 3390/en12101867

Verma AS, Vedvik NP, Haselbach PU, Gao Z, Jiang Z (2019e) Comparison of numerical modelling techniques for impact investigation on a wind turbine blade. Compos Struct 209:856-878. https:// doi.org/10.1016/j.compstruct.2018.11.001

Verma, A.S., Zhao, Y., Gao, Z. and Vedvik, N.P., (2019f). Explicit structural response-based methodology for assessment of operational limits for single blade installation for offshore wind turbines. In Proceedings of the Fourth International Conference in Ocean Engineering (ICOE2018) (pp. 737-750). Springer, Singapore. https://doi.org/10.1007/978-981-13-3134-3_55

Verma AS, Jiang Z, Gao Z, Vedvik NP (2020a) Effects of passive tuned mass damper on blade root impacts during offshore mating process. Mar Struct 72(2020):102778. https://doi.org/10.1016/j.marstruc. 2020.102778

Verma AS, Castro SG, Jiang Z, Teuwen JJE (2020b) Numerical investigation of rain droplet impact on offshore wind turbine blades under different rainfall conditions: a parametric study. Composite Structures, p 112096. https://doi.org/10.1016/j.compstruct.2020. 112096

Wind Europe (2017a) The European offshore wind industry - key trends and statistics

Wind Europe (2017b) Wind in power 2017: annual combined onshore and offshore wind energy statistics

Zhou S, Shan B, Xiao Y, Li C, Hu G, Song X, Liu Y, Hu Y (2017) Directionality effects of aligned wind and wave loads on a y-shape semi-submersible floating wind turbine under rated operational conditions. Energies 10(12):2097. https://doi.org/10.3390/en10122097 